\title{
Influences of in-cloud aerosol scavenging parameterizations on aerosol concentrations and wet deposition in ECHAM5-HAM
}

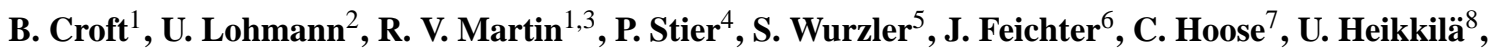 \\ A. van Donkelaar ${ }^{1}$, and S. Ferrachat ${ }^{2}$ \\ ${ }^{1}$ Department of Physics and Atmospheric Science, Dalhousie University, Halifax, Canada \\ ${ }^{2}$ Institute of Atmospheric and Climate Science, ETH Zurich, Zurich, Switzerland \\ ${ }^{3}$ Harvard-Smithsonian Center for Astrophysics, Cambridge, MA, USA \\ ${ }^{4}$ Atmospheric, Oceanic, and Planetary Physics, University of Oxford, Oxford, UK \\ ${ }^{5}$ Landesamt fur Umwelt, Natur und Verbraucherschutz NRW (LANUV), Recklinghausen, Germany \\ ${ }^{6}$ Max Planck Institute for Meteorology, Hamburg, Germany \\ ${ }^{7}$ Department of Geosciences, University of Oslo, Oslo, Norway \\ ${ }^{8}$ Bjerknes Centre for Climate Research, Bergen, Norway
}

Received: 23 September 2009 - Published in Atmos. Chem. Phys. Discuss.: 21 October 2009

Revised: 6 February 2010 - Accepted: 8 February 2010 - Published: 15 February 2010

\begin{abstract}
A diagnostic cloud nucleation scavenging scheme, which determines stratiform cloud scavenging ratios for both aerosol mass and number distributions, based on cloud droplet, and ice crystal number concentrations, is introduced into the ECHAM5-HAM global climate model. This scheme is coupled with a size-dependent in-cloud impaction scavenging parameterization for both cloud droplet-aerosol, and ice crystal-aerosol collisions. The aerosol mass scavenged in stratiform clouds is found to be primarily ( $>90 \%$ ) scavenged by cloud nucleation processes for all aerosol species, except for dust $(50 \%)$. The aerosol number scavenged is primarily (>90\%) attributed to impaction. 99\% of this impaction scavenging occurs in clouds with temperatures less than $273 \mathrm{~K}$. Sensitivity studies are presented, which compare aerosol concentrations, burdens, and deposition for a variety of incloud scavenging approaches: prescribed fractions, a more computationally expensive prognostic aerosol cloud processing treatment, and the new diagnostic scheme, also with modified assumptions about in-cloud impaction and nucleation scavenging. Our results show that while uncertainties in the representation of in-cloud scavenging processes can lead to differences in the range of $20-30 \%$ for the predicted annual, global mean aerosol mass burdens, and near to $50 \%$ for accumulation mode aerosol number burden, the differences in predicted aerosol mass concentrations can be up to
\end{abstract}

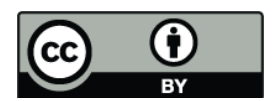

Correspondence to: B. Croft (croft@mathstat.dal.ca) one order of magnitude, particularly for regions of the middle troposphere with temperatures below $273 \mathrm{~K}$ where mixed and ice phase clouds exist. Different parameterizations for impaction scavenging changed the predicted global, annual mean number removal attributed to ice clouds by seven-fold, and the global, annual dust mass removal attributed to impaction by two orders of magnitude. Closer agreement with observations of black carbon profiles from aircraft (increases near to one order of magnitude for mixed phase clouds), midtroposphere ${ }^{210} \mathrm{~Pb}$ vertical profiles, and the geographic distribution of aerosol optical depth is found for the new diagnostic scavenging scheme compared to the prescribed scavenging fraction scheme of the standard ECHAM5-HAM. The diagnostic and prognostic schemes represent the variability of scavenged fractions particularly for submicron size aerosols, and for mixed and ice phase clouds, and are recommended in preference to the prescribed scavenging fractions method.

\section{Introduction}

Atmospheric aerosols significantly influence climate since they both reflect and absorb radiation (direct effects), and modify cloud properties (indirect radiative effects) (Twomey, 1991; Charlson et al., 1992). Aerosols enter cloud droplets, or ice crystals by the nucleation process when they act as cloud condensation, or ice nuclei, and secondly by the process of impaction with the cloud droplets or ice crystals

Published by Copernicus Publications on behalf of the European Geosciences Union. 
(Pruppacher and Klett, 1997). A fraction of these droplets and crystals will then grow into precipitation particles that are removed from the atmosphere. Global climate models (GCMs) must accurately represent these nucleation and impaction processes that incorporate aerosols into cloud droplets and ice crystals in order to predict reasonable threedimensional aerosol distributions, and deposition. Differences in aerosol prediction between global models have been attributed in part to differences in the representation of these removal processes (Textor et al., 2006).

This study will present a comparison between the variety of treatments for in-cloud nucleation and impaction scavenging that have been implemented in global models, including prescribed fractions, and diagnostic and prognostic treatments for the in-droplet and in-crystal aerosols. Using the ECHAM5-HAM GCM, we will examine the strengths and weaknesses of the various parameterization and investigate whether uncertainties in in-cloud scavenging parameterizations lead to any significant differences in predicted aerosol concentrations, burdens and deposition. Earlier work by Ghan and Easter (2006) showed that a diagnostic scheme under-predicted global mean aerosol burdens by $20 \%$ as compared to a prognostic representation of the in-droplet aerosols. However, that study did not explore the bias of using prescribed scavenging fractions, and did not examine sensitivities related to the scavenging of aerosols by ice crystals as we will do for this study.

Prescribed aerosol scavenging fractions have traditionally been implemented in many GCMs, including ECHAM5HAM, and some models have simply assumed that $100 \%$ of the aerosol in a cloud is scavenged into the cloud droplets and ice crystals (e.g., Barth et al., 2000; Chin et al., 2000; Takemura et al., 2002; Stier et al., 2005; Tie et al., 2005). This approach is desirable for the low computational expense. Other global models use diagnostic in-cloud scavenging schemes, which diagnose the total aerosol scavenged fraction at each model time-step based on selected parameters related to cloud droplet and ice crystal nucleation and impaction processes, such as the supersaturation, updraft speed, and aerosol size and composition (e.g., Adams and Seinfeld, 2002; Gong et al., 2003). By the term diagnostic, we mean that the total aerosol fraction scavenged into the cloud droplets and ice crystals is diagnosed at each model timestep, and unlike in a prognostic scavenging scheme, aerosol in-droplet and in-crystal concentrations are not passed between model time-steps. Prognostic aerosol cloud processing schemes have also been recently developed, which do pass aerosol in-droplet, and in-crystal aerosol concentrations between model time-steps (e.g., Ghan and Easter, 2006; Hoose et al., 2008a,b). In this study, we introduce a new diagnostic aerosol scavenging scheme into the ECHAM5-HAM, and compare with additional simulations that treat in-cloud scavenging either by the prescribed fractions, or with the prognostic scheme of Hoose et al. (2008a,b).
Our new diagnostic scavenging scheme includes a physically detailed size-dependent parameterization of in-cloud impaction scavenging. This will allow us to examine the relative contributions of the nucleation and impaction scavenging processes to total in-cloud scavenging in the global context. Jacobson (2003) found for a one-dimensional study that aerosol mass was primarily scavenged by nucleation, whereas aerosol number was primarily scavenged by impaction processes. Recently, Baumgardner et al. (2008) have suggested that for black carbon, scavenging by ice crystals is dominated by impaction as opposed to nucleation processes.

Currently, the representation of impaction scavenging varies considerably between global models, and is a source of uncertainty in the in-cloud scavenging parameterizations. Some global models include impaction scavenging implicitly in the prescribed scavenging ratios (Stier et al., 2005). Other models have an explicit impaction scavenging parameterization. For example, Gong et al. (2003) used a parameterized equation as a function of the mean cloud droplet and aerosol radii, and cloud droplet number concentration. Hoose et al. (2008a,b) used prescribed collection kernels for each aerosol mode of ECHAM5-HAM. In this study, we compare the prescribed kernel approach of Hoose et al. $(2008 \mathrm{a}, \mathrm{b})$ with our physically detailed size-dependent cloud droplet-aerosol, and ice crystal-aerosol impaction scavenging parameterization, and additional sensitivity simulations that have zero impaction scavenging. Our new physically detailed parameterization selects mean mass and number impaction scavenging coefficients from a look-up table as a function of mean cloud droplet radius (assuming a gamma distribution), median radius of the lognormal aerosol mass or number distribution, and cloud droplet number concentration. This is coupled with an ice-crystal-aerosol in-cloud impaction scavenging parameterization that depends on the monodisperse ice crystal radius, ice crystal number concentration, and the median aerosol radius of the mass and number distributions. In this study, we will examine the relative uncertainty in predicted aerosol concentrations that may be attributed to either nucleation or impaction processes for all cloud temperatures.

The next section gives a description of the ECHAM5 GCM, coupled to the aerosol scheme HAM, and includes the details of the various in-cloud scavenging parameterizations. Section 3 summarizes the impacts of the in-cloud scavenging parameterizations on the global aerosol three-dimensional distributions and removal rates. Section 4 presents a comparison with observations of aerosol wet deposition, vertical profiles of black carbon concentrations, marine boundary layer size distributions, and aerosol optical depth. This also includes a sub-section on the global modeling of ${ }^{7} \mathrm{Be}$ and ${ }^{210} \mathrm{~Pb}$, which are useful as passive tracers to examine in-cloud scavenging parameterizations. Section 5 gives a summary and conclusions. 


\section{Model description}

ECHAM5 is the fifth generation atmospheric general circulation model (GCM) developed at the Max-Planck Institute for Meteorology (Roeckner et al., 2003), and evolved from the model of the European Centre for Medium Range Weather Forecasting (ECMWF). The model solves prognostic equations for vorticity, divergence, temperature and surface pressure using spheric harmonics with triangular truncation. Water vapor, cloud liquid and ice water are transported using a semi-Lagrangian scheme (Lin and Rood, 1996). Additionally, for this study we have implemented the prognostic equations for cloud liquid and ice water, mass and number following Lohmann et al. (2007), and the cirrus scheme of Lohmann and Kärcher (2002). Convective clouds, and transport are based on the mass-flux scheme of Tiedtke (1989) with modifications following Nordeng (1994). The solar radiation scheme has 6 spectral bands (Cagnazzo et al., 2007) and the infrared has 16 spectral bands (Mlawer et al., 1997; Morcrette et al., 1998).

The GCM is coupled to the Hamburg Aerosol Model (HAM), which is described in detail in Stier et al. (2005). The five aerosol species (sulfate, black carbon, particulate organic matter, sea salt and dust) are represented by seven lognormal modes, 4 internally mixed/soluble modes - nucleation (NS), Aitken (KS), accumulation (AS), and coarse (CS ), - and 3 insoluble modes - Aitken (KI), accumulation (AI), and coarse (CI). The count median radius for each mode is calculated from the aerosol mass and number concentrations of each mode, which are allowed to vary independently, and with a fixed standard deviation for each mode. Aerosol mass and number are transferred between the modes by the processes of sulfuric acid condensation, and also coagulation between aerosols. All results presented in this study are from a one year simulation, following a three months spin-up period, except 6 months spin-up period for simulations with ${ }^{210} \mathrm{~Pb}$ and ${ }^{7} \mathrm{Be}$. All simulations are nudged towards the meteorological conditions of the year 2001. The nudging approach, combined with aerosol-radiation de-coupling, was chosen in order to have the same dust and sea salt emissions in all simulations. We chose the year 2001 since that was a neutral year for the El Nino Southern Oscillation. The natural emissions of sea salt, dust, and DMS from the oceans are calculated on-line, based on the meteorology of the model. Emissions for all other aerosol species are taken from the AEROCOM emission inventory, and are representative for the year 2000 (Dentener et al., 2006b). The aerosol emissions and the removal processes of sedimentation, and dry deposition are described in detail in Stier et al. (2005). For this study, the below-cloud scavenging parameterization of Croft et al. (2009) has been implemented. This physically detailed below-cloud impaction scavenging parameterization uses look-up tables to select scavenging coefficients that represent the collection of aerosols by rain and snow below clouds based on aerosol size and precipitation rates.

\subsection{In-cloud aerosol scavenging parameterizations}

\subsubsection{Current in-cloud scavenging}

In the standard ECHAM5-HAM model, in-cloud scavenging ratios are prescribed for each of the seven log-normal modes. These ratios depend on the cloud temperature, distinguishing between warm, mixed and ice clouds, and also depend on the cloud type, either stratiform or convective. The cloud scavenging ratios are presented in Table 1. The control (CTL) simulation is conducted with these prescribed ratios of the standard ECHAM5-HAM model. The rate of change of tracer $i$ is

$\frac{\Delta C_{i}}{\Delta t}=R_{i} C_{i} f^{\mathrm{cl}}\left(\frac{f^{\text {liq }} Q^{\text {liq }}}{C_{\text {liq }}}+\frac{f^{\text {ice }} Q^{\text {ice }}}{C_{\text {ice }}}\right)$

where $R_{i}$ is the prescribed in-cloud scavenging ratio, $C_{i}$ is the mixing ratio of tracer $i, f^{\mathrm{cl}}$ is the cloud fraction, $C_{\mathrm{liq}}$ and $C_{\text {ice }}$ are the cloud liquid and ice water mixing ratios, respectively, $Q^{\text {liq }}$ and $Q^{\text {ice }}$ are the respective sums of the conversion rates of cloud liquid and ice to precipitation by the processes of autoconversion, accretion and aggregation, and $f^{\text {liq }}$ and $f^{\text {ice }}$ are the respective liquid and ice fraction of the cloud water, and $\Delta t$ is the time-step. Each prescribed in-cloud scavenging ratio treats impaction scavenging implicitly together with nucleation scavenging in the current model.

\subsubsection{New diagnostic in-cloud nucleation scavenging}

For the new nucleation scavenging parameterization, the scavenging ratios for stratiform clouds are diagnosed from the cloud droplet number concentration (CDNC), and the ice crystal number concentration (ICNC). The convective incloud scavenging for all simulations uses the prescribed ratios given in Table 1, and described in detail in Stier et al. (2005). For stratiform clouds, both the CDNC and ICNC are prognostic variables in the version of the ECHAM5-HAM model used here, and the cloud microphysics is described in detail in Lohmann et al. (2007). In our model version, and for all simulations presented in this study, the activation of aerosol particles to form cloud droplets is parameterized using the Ghan et al. (1993) scheme. The number of activated aerosols $N_{\text {act, Ghan }}$ is given by

$N_{\text {act, Ghan }}=\frac{\omega N_{>35 \mathrm{~nm}}}{\omega+\beta N_{>35 \mathrm{~nm}}}$

and

$\omega=\bar{\omega}+0.7 \sqrt{\mathrm{TKE}}$.

$\omega$ is the updraft velocity, $\bar{\omega}$ is the large-scale vertical velocity, TKE is the turbulent kinetic energy, $\beta$ is $0.0034 \mathrm{~cm}^{4} \mathrm{~s}^{-1}$, and $N_{>35 \mathrm{~nm}}$ is the total number of soluble/internally mixed aerosols with radii $>35 \mathrm{~nm}$.

For the new diagnostic nucleation scavenging scheme, the total number of aerosols to be scavenged into the cloud 
Table 1. In-cloud scavenging ratios for each of the seven log-normal modes of the ECHAM5-HAM dependent on the cloud type and temperature (warm: $T>273.15 \mathrm{~K}$, mixed: $238.15<T \leq 273.15 \mathrm{~K}$, ice: $T \leq 238.15 \mathrm{~K}$ ) following Stier et al. (2005).

\begin{tabular}{lcccc}
\hline Mode & Warm Stratiform & Mixed Stratiform & Ice Stratiform & Convective \\
\hline Nucleation Soluble (NS) & 0.10 & 0.10 & 0.00 & 0.20 \\
Aitken Soluble (KS) & 0.25 & 0.40 & 0.10 & 0.60 \\
Accumulation Soluble (AS) & 0.85 & 0.75 & 0.10 & 0.99 \\
Coarse Soluble (CS) & 0.99 & 0.75 & 0.10 & 0.99 \\
Aitken Insoluble (KI) & 0.20 & 0.10 & 0.10 & 0.20 \\
Accumulation Insoluble (AI) & 0.40 & 0.40 & 0.10 & 0.40 \\
Coarse Insoluble (CI) & 0.40 & 0.40 & 0.10 & 0.40 \\
\hline
\end{tabular}

droplets and ice crystals at each time-step is the sum of the CDNC and ICNC. For clouds with temperatures $>238.15 \mathrm{~K}$, the liquid cloud droplets, and those frozen heterogeneously to ice crystals in our model, both originate from Ghan et al. (1993) activation scheme. Thus, we can treat the total number of droplets and crystals as the total number of aerosols scavenged by nucleation. This total number must be apportioned between the four soluble/internally mixed aerosol modes in a manner that is consistent with the activation scheme as follows,

$N_{j, \text { scav }}=(\mathrm{CDNC}+\mathrm{ICNC}) \cdot \frac{N_{j>35 \mathrm{~nm}}}{N_{>35 \mathrm{~nm}}}$

where $N_{j, \text { scav }}$ is the total number of aerosols to be scavenged from the $j$-th mode, for $j=\mathrm{NS}, \mathrm{KS}, \mathrm{AS}, \mathrm{CS} . N_{j>35} \mathrm{~nm}$ is the aerosol number for the $j$-th mode having radii greater than $35 \mathrm{~nm}$, and $N_{>35} \mathrm{~nm}$ is the number of aerosols having radii greater than $35 \mathrm{~nm}$ summed over all the soluble/internally mixed modes. Thus, if tracer $i$ is a soluble/internally mixed number mixing ratio, we have the following nucleation scavenging fraction,

$R_{i, \mathrm{nuc}}=\frac{N_{j, \mathrm{scav}}}{N_{j}}$.

where $N_{j}$ is the total number of aerosols in the $j$-th mode. The insoluble modes are assumed to have nucleation scavenging ratios of zero, but the impaction scavenging ratio might not be zero.

The scavenged fraction of the mass distribution is not set equal to the scavenged fraction of the number distribution. To determine the fractional scavenging of the mass distribution, the aerosols in each mode are assumed to be scavenged progressively from the largest to the smallest size. Thus, for each mode a critical radius, $r_{j, \text { crit }}$, can be determined that has exactly $N_{j, \text { scav }}$ in the lognormal tail of the number distribution. The total aerosol mass to be scavenged from the $j$-th mode is that mass of the lognormal tail that lies above $r_{j \text {,crit }}$.
To calculate $r_{j, \text { crit }}$, the cumulative log-normal size distribution, $F_{N}\left(r_{j, \text { crit }}\right)$, is employed, where

$$
\begin{aligned}
& F_{N}\left(r_{j, \text { crit }}\right)=N_{j}-N_{j, \text { scav }}=\frac{N_{j}}{2}+\frac{N_{j}}{2} \text { erf } \\
& \left(\frac{\ln \left(r_{j, \text { crit }} / r_{\mathrm{pg}}\right)}{\sqrt{2} \ln \sigma_{g}}\right)
\end{aligned}
$$

and $r_{\mathrm{pg}}$ is the count median radius for the $j$-th mode, $\sigma_{g}$ is the standard deviation for the respective mode and erf refers to the error function. By taking a rational approximation to the inversion of the error function, the above equation can be solved for $r_{j, \text { crit }}$. Thus, the critical radius is given by,

$$
\begin{aligned}
& r_{j, \text { crit }}=r_{\mathrm{pg}} . \\
& \left(\exp \left(\sqrt{2} \ln \sigma_{g} \cdot \operatorname{erf}^{-1}\left(1-\left(2 \cdot(\mathrm{CDNC}+\mathrm{ICNC}) \cdot \frac{N_{j>35} \mathrm{~nm}}{N_{j} N_{>35 \mathrm{~nm}}}\right)\right)\right)\right)
\end{aligned}
$$

where $N_{j, \text { scav }}$ has been replaced the explicit expression in Eq. (4). Therefore, if tracer $i$ is a soluble/internally mixed mass mixing ratio we have the following nucleation scavenging fraction for the mass distribution,

$R_{i, \text { nuc }}=\frac{\int_{r_{j, \text { crit }}}^{\infty} m_{i, j}\left(r_{\mathrm{p}}\right) d r_{\mathrm{p}}}{\int_{0}^{\infty} m_{i, j}\left(r_{\mathrm{p}}\right) d r_{\mathrm{p}}}$

where $m_{i, j}\left(r_{\mathrm{p}}\right)$ is the lognormal mass distribution for the $i$-th aerosol species of the $j$-th mode, and $r_{\mathrm{p}}$ is the aerosol radius. The lognormal mass distribution has the same standard deviation as the number distribution for any given mode, as described in Stier et al. (2005), and the mass median radius for the lognormal distribution $\left(r_{\mathrm{pg}, \mathrm{m}}\right)$ is related to the count median radius $\left(r_{\mathrm{pg}}\right)$ following

$r_{\mathrm{pg}, \mathrm{m}}=r_{\mathrm{pg}} \cdot \exp \left(3 \ln ^{2} \sigma_{g}\right)$.

The nucleation scavenging for temperatures below $238.15 \mathrm{~K}$ is different, since the ice crystals originate from homogeneous freezing at these temperatures. Homogeneous freezing does not require an ice nucleus. The version of the ECHAM5-HAM model used here includes the cirrus scheme described in Lohmann and Kärcher (2002). The total ICNC 


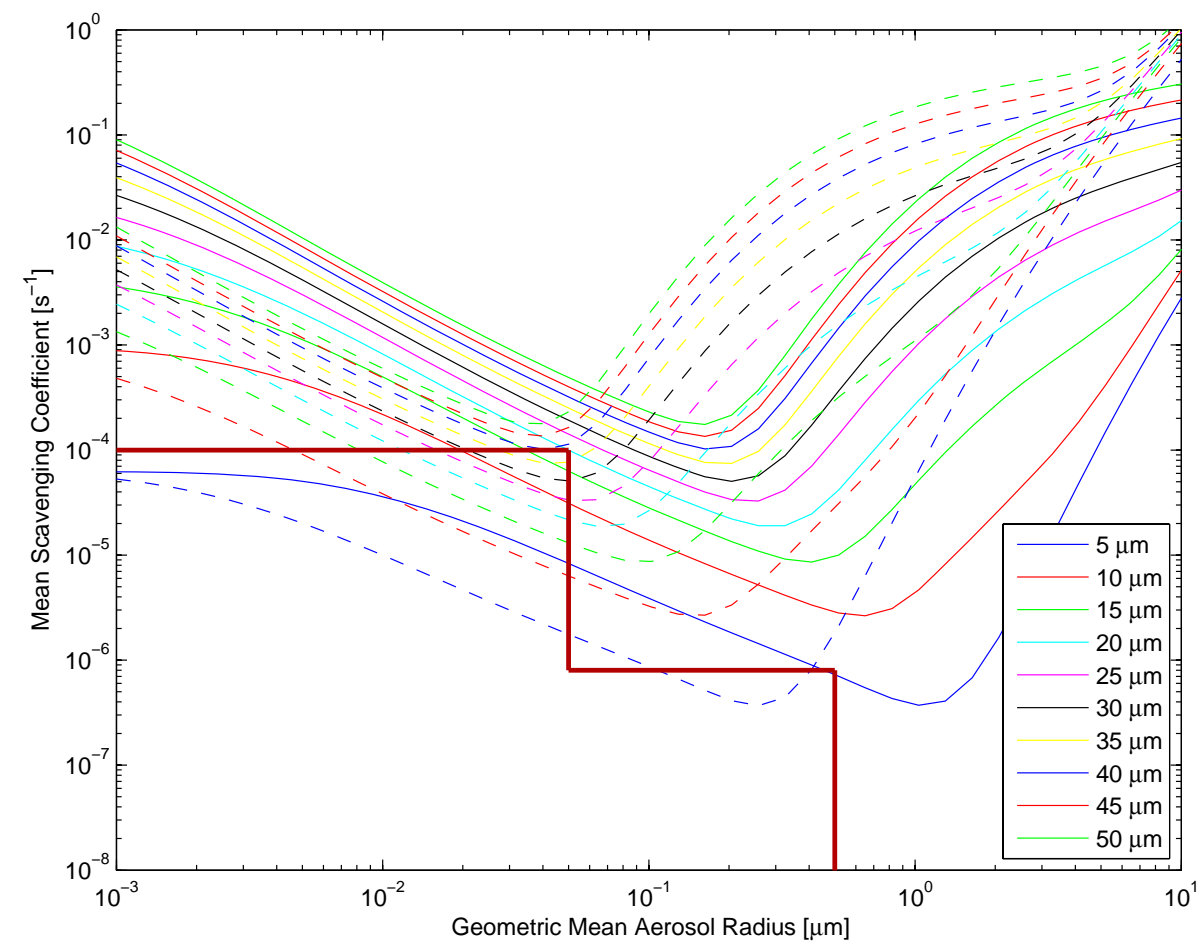

Fig. 1. In-cloud mean mass (dashed lines) and number (solid lines) impaction scavenging coefficients ( $\mathrm{s}^{-1}$ ) as a function of geometric mean aerosol radius, for a cloud droplet number concentration of $40 \mathrm{~cm}^{-3}$, and for a range of mean cloud droplet radii from 5 to $50 \mu \mathrm{m}$. The prescribed cloud droplet collection coefficients of Hoose et al. (2008a,b) are shown by the red thick steps.

is assumed to be equal to the total number of aerosols to be scavenged, but the modes are scavenged progressively from the largest soluble/internally mixed mode (CS) to the smallest (KS), which is consistent with the homogeneous freezing parameterization of our model. As a result, the calculation of the critical radius, is only done for the mode that is found to be partially scavenged, after all larger modes are fully scavenged. The nucleation scavenging ratio is set to zero for all modes smaller than the partially scavenged mode, and for all insoluble modes.

\subsubsection{New size-dependent in-cloud impaction scavenging}

For the aerosol-cloud droplet impaction scavenging, the mean mass scavenging coefficients, in units of inverse time, are

$\Lambda_{\mathrm{m}}\left(r_{\mathrm{pg}, \mathrm{m}}\right)=\frac{\int_{0}^{\infty} \Lambda\left(r_{\mathrm{pg}, \mathrm{m}}\right) r_{\mathrm{p}}^{3} n\left(r_{\mathrm{p}}\right) d r_{\mathrm{p}}}{\int_{0}^{\infty} r_{\mathrm{p}}^{3} n\left(r_{\mathrm{p}}\right) d r_{\mathrm{p}}}$,

and the mean number scavenging coefficients are

$\Lambda_{\mathrm{n}}\left(r_{\mathrm{pg}}\right)=\frac{\int_{0}^{\infty} \Lambda\left(r_{\mathrm{pg}}\right) n\left(r_{\mathrm{p}}\right) d r_{\mathrm{p}}}{\int_{0}^{\infty} n\left(r_{\mathrm{p}}\right) d r_{\mathrm{p}}}$,

where $n\left(r_{\mathrm{p}}\right)$ is the aerosol lognormal number distribution, $r_{\mathrm{p}}$ is the aerosol radius, and $r_{\mathrm{pg}}$, and $r_{\mathrm{pg}, \mathrm{m}}$ are the median aerosol radius for the number and mass distribution, respectively. The scavenging coefficient $\Lambda\left(r_{\mathrm{pg}}\right)$, also in units of inverse time, is defined as

$\Lambda\left(r_{\mathrm{pg}}\right)=\int_{0}^{\infty} \pi R_{\text {liq }}^{2} U_{\mathrm{t}}\left(R_{\mathrm{liq}}\right) E\left(R_{\mathrm{liq}}, r_{\mathrm{pg}}\right) n\left(R_{\mathrm{liq}}\right) d R_{\text {liq }}$

where $R_{\text {liq }}$ is the cloud droplet radii, $U_{\mathrm{t}}\left(R_{\text {liq }}\right)$ is the terminal velocity of the cloud droplet, $E\left(R_{\mathrm{liq}}, r_{\mathrm{p}}\right)$ is the collision efficiency between the aerosol and cloud droplet, and $n\left(R_{\text {liq }}\right)$ is the cloud droplet number distribution, which is assumed to be a Gamma distribution. We find the collision efficiencies and terminal velocities following the approach outlined in detail in Croft et al. (2009). Figure 1 shows the impaction scavenging coefficients for a CDNC of $40 \mathrm{~cm}^{-3}$ as an example. Note that for this figure, the aerosol radii are the geometric mean radii for the assumed lognormal aerosol distribution. The scavenging coefficients have a minimum for aerosol radii near to $0.1 \mu \mathrm{m}$. For aerosols with radii smaller than $0.1 \mu \mathrm{m}$, Brownian motion increases their collection by the cloud droplets, whereas the inertia of larger aerosols increases their collection. At the minimum, neither of these forces is dominant. The impaction scavenging coefficients are compiled in look-up tables. Thus, if tracer $i$ is a mass mixing ratio, the scavenging fraction for cloud droplet-aerosol impaction is

$R_{i, \text { imp }, \text { liq }}=\Lambda_{\mathrm{m}}\left(r_{\mathrm{pg}, \mathrm{m}}\right) \Delta t$ 
and likewise if tracer $i$ is a number mixing ratio, but using $\Lambda_{\mathrm{n}}\left(r_{\mathrm{pg}}\right)$. Both soluble/internally mixed, and insoluble aerosol modes are scavenged similarly by impaction.

Since the ECHAM5-HAM model assumes that the ice crystals are monodiperse, we do not integrate over an ice crystal number distribution to determine the scavenging ratio. The scavenged fraction due to aerosol-ice crystal impaction is defined as

$R_{i, \text { imp }, \text { ice }}=K\left(R_{\text {ice }}, r_{\mathrm{pg}}\right) \cdot \mathrm{ICNC} \cdot \Delta t$

where ICNC is the ice crystal number concentration, and $R_{\text {ice }}$ is the radius of the maximum dimension of the ice crystal, and $r_{\mathrm{pg}}$ is the median radius of the aerosol number, or mass distribution, and $K\left(R_{\text {ice }}, r_{\mathrm{p}}\right)$ is the collection kernel given by,

$K\left(R_{\text {ice }}, r_{\mathrm{pg}}\right)=\pi R_{\text {ice }}^{2} U_{\mathrm{t}}\left(R_{\text {ice }}\right) E\left(R_{\text {ice }}, r_{\mathrm{pg}}\right)$

where $U_{\mathrm{t}}\left(R_{\text {ice }}\right)$ is the ice crystal terminal velocity and $E\left(R_{\text {ice }}, r_{\mathrm{pg}}\right)$ is the collection efficiency for ice crystal-aerosol collisions. The size of the monodisperse crystals is calculated depending on the ice water content and the ICNC as described in Lohmann et al. (2008). The collection kernels are taken from Miller and Wang (1991) in units of $\mathrm{cm}^{3} \mathrm{~s}^{-1}$ and are compiled in look-up tables in our model. For temperatures less than $238.15 \mathrm{~K}$, we assume that all crystals are columns, and for temperatures greater than $238.15 \mathrm{~K}$, all crystals are assumed to be plates (Lohmann et al., 2008). There is a lack of collection data for ice crystals with radii less than about $30 \mu \mathrm{m}$. For these crystal sizes, we use the same collection kernels as for liquid droplets, as described in detail in Croft et al. (2009). Ice crystals of this size are often assumed to be quasi-spherical (Spichtinger and Gierens, 2009).

Figure 2 shows the collection kernels for ice plates and columns for a selection of Reynold's numbers, and also for droplets with radii of $30 \mu \mathrm{m}$ and less. In our look-up table approach, the Reynold's number is related to the size of the ice crystals following the crystal dimensions given in Martin et al. (1980), and Miller and Wang (1989). Similar to droplets, ice crystals have a scavenging minimum, but this minimum shifts due to the various geometries of the crystals. For particle sizes near the scavenging minimum, plates are more efficient scavengers than columns. Miller and Wang (1991) attribute this to the formation of eddies in the flow around the plate geometry, which increases their collection. There is also a zone of zero-scavenging (ZSZ) for aerosols in the $1-2 \mu \mathrm{m}$ size range, which occurs since the sum of all forces at work results in a near-zero probability of collision between the aerosol and falling crystal. While the scavenging coefficients presented in Figs. 1 and 2 are reasonable, there are considerable uncertainties associated the parameterization of impaction scavenging. Assumptions about the collector particle size distribution, and the collection efficiency, particularly associated with thermophoretic, turbulent, and electric forces can cause the scavenging coefficients to differ by up to an order of magnitude (Wang et al., 1978; Miller and Wang, 1989). For the parameterization of impaction scavenging of aerosols by cloud droplets, we use separate scavenging coefficients for aerosol mass and number, but we do not make this separation for ice-crystal-aerosol impaction scavenging. This is an additional uncertainty related to the scavenging of aerosols by ice crystals that we do not address here, but that should be considered in future work.

Similar to Eq. (1), the local rate of change of the tracer $C_{i}$ due to in-cloud scavenging by both nucleation and impaction is

$$
\begin{aligned}
& \frac{\Delta C_{i}}{\Delta t}=C_{i} f^{\mathrm{cl}}\left(\frac{\left(R_{i, \text { nuc }}+R_{i, \text { imp }, \text { liq }}\right) f^{\text {liq }} Q^{\text {liq }}}{C_{\text {liq }}}\right. \\
& \left.+\frac{\left(R_{i, \text { nuc }}+R_{i, \text { imp,ice }}\right) f^{\text {ice }} Q^{\text {ice }}}{C_{\text {ice }}}\right)
\end{aligned}
$$

where $f^{\text {liq }}$ and $f^{\text {ice }}$ are the respective liquid and ice water fractions of the total cloud water, $f^{\mathrm{cl}}$ is the cloud fraction, $C_{\text {liq }}$ and $C_{\text {ice }}$ are the cloud liquid and ice water content, respectively, and $Q^{\text {liq }}$ and $Q^{\text {ice }}$ are the respective sums of the conversion rates of cloud liquid and ice to precipitation by the processes of autoconversion, accretion and aggregation. This diagnostic scavenging approach is implemented in simulation DIAG-FULL.

\subsubsection{Prognostic in-cloud scavenging}

In this study, we also use the prognostic in-cloud aerosol processing scheme for stratiform clouds developed by Hoose et al. $(2008 \mathrm{a}, \mathrm{b})$ (simulation PROG-AP). This scheme treats the aerosol mass and number concentrations in the cloud droplets and ice crystals as prognostic species, which are passed between model time-steps. The processes of nucleation and impaction scavenging, evaporation, sublimation, freezing and melting are represented for this parameterization. The methodology is described in detail in Hoose et al. (2008a,b). Unlike the new diagnostic scheme, the prognostic scheme currently applies the same nucleation scavenging ratio to both the aerosol mass and number distributions for any given aerosol mode, grid box and time-step, as opposed to having separate mass and number nucleation scavenging ratios. One other difference is that the in-cloud impaction scavenging for the time being implements the prescribed kernels of Table 2 as opposed to the physically detailed sizedependent impaction parameterization of the new diagnostic scheme in the simulation DIAG-FULL.

\subsubsection{In-cloud scavenging sensitivity simulations}

We implement several variations to the new diagnostic scheme as sensitivity tests. All simulations conducted for this study are summarized in Table 3. Simulation DIAG2 replaces the size-dependent in-cloud impaction parameterization of simulation DIAG-FULL with the prescribed 

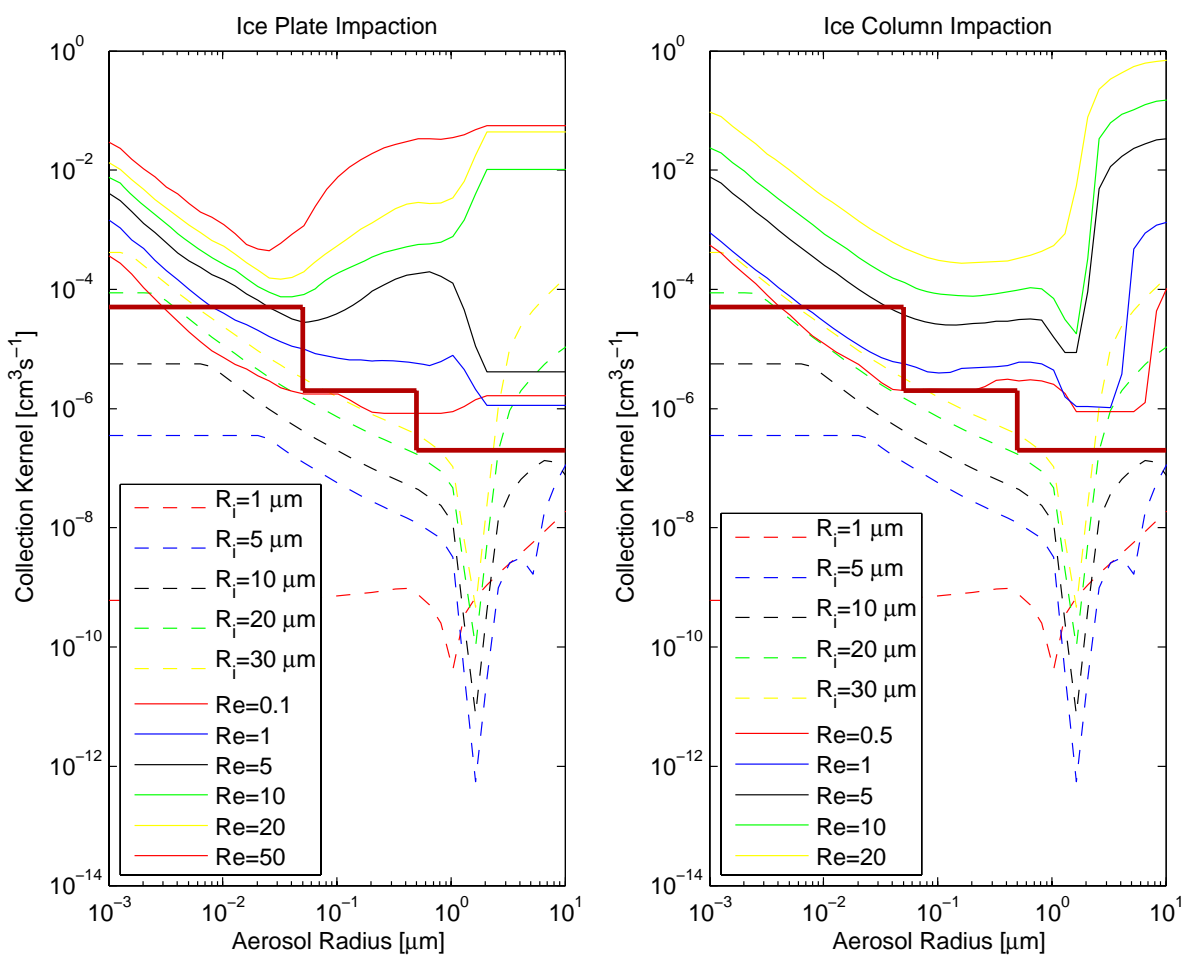

Fig. 2. Impaction scavenging kernels $\left(\mathrm{cm}^{3} \mathrm{~s}^{-1}\right)$ for in-cloud ice crystal-aerosol collisions as a function of aerosol radius, and ice crystal Reynold's number (Re) following Miller and Wang (1991) (solid lines), and for both columns and plates. The dashed lines are for dropletaerosol collisions. $\mathrm{R}_{i}$ indicates collector radius. The prescribed ice crystal collection kernels of Hoose et al. (2008a,b) are shown by the red thick steps.

impaction kernels of Hoose et al. (2008a,b) given in Table 2. DIAG2 is otherwise the same as DIAG-FULL. Simulation DIAG1 differs from simulation DIAG2 only in that the nucleation scavenging is changed such that the the mass nucleation scavenging ratios are set equal to the diagnosed number nucleation scavenging ratios. Two additional sensitivity studies are done to examine the prescribed ratio approach. $100 \%$ of the aerosols in clouds are assumed to be scavenged into the droplets or crystals for the simulation F100. This simplistic assumption has been used in global models (e.g., Barth et al., 2000). The simulation F100-INT is similar except that $100 \%$ of the soluble/internally mixed aerosols in clouds are assumed to be cloud-borne, and $0 \%$ of the insoluble aerosol is scavenged into the cloud droplets or crystals. All of our simulations that implement scavenging by prescribed fractions treat the process of impaction implicitly together with nucleation in the prescribed fractions. To examine the relative importance of impaction, particularly related to aerosol vertical profiles, we set all in-cloud impaction scavenging to zero for the simulations DIAG-FULL-noimp and PROG-APnoimp, which are otherwise identical to DIAG-FULL and PROG-AP, respectively.
Table 2. In-cloud impaction scavenging kernels $\left(\mathrm{m}^{3} \mathrm{~s}^{-1}\right)$ for aerosol-droplet and aerosol-ice crystal collision for each of the seven log-normal modes of the ECHAM5-HAM following Hoose et al. (2008a,b).

\begin{tabular}{lll}
\hline Mode & Droplets & Crystals \\
\hline Nucleation Soluble (NS) & $2.5 \times 10^{-12}$ & $5.0 \times 10^{-11}$ \\
Aitken Soluble (KS) & $2.5 \times 10^{-12}$ & $5.0 \times 10^{-11}$ \\
Accumulation Soluble (AS) & $2.0 \times 10^{-14}$ & $2.0 \times 10^{-12}$ \\
Coarse Soluble (CS) & 0.0 & $2.0 \times 10^{-13}$ \\
Aitken Insoluble (KI) & $2.5 \times 0^{-12}$ & $5.0 \times 10^{-11}$ \\
Accumulation Insoluble (AI) & $2.0 \times 10^{-14}$ & $2.0 \times 10^{-12}$ \\
Coarse Insoluble (CI) & 0.0 & $2.0 \times 10^{-13}$ \\
\hline
\end{tabular}

\section{Results of the global simulations}

\subsection{Aerosol scavenged fractions}

Figure 3 shows a frequency plot of the aerosol mass and number scavenged fractions for the DIAG-FULL simulation as compared to the prescribed ratios of Stier et al. (2005), which are implemented for the CTL simulation. Particularly for mixed phase clouds, the scavenged fractions deviate 
Table 3. The simulations conducted for this study are summarized in this table.

\begin{tabular}{ll}
\hline Simulation & Description \\
\hline CTL & Control simulation using prescribed in-cloud scavenging ratios from Table 1 \\
F100 & Assuming $100 \%$ of aerosols in clouds are cloud-borne for all aerosol modes \\
F100-INT & $\begin{array}{l}\text { Assuming } 100 \% \text { of soluble/internally mixed aerosols in clouds are cloud-borne, and } 0 \% \text { of insoluble } \\
\text { aerosols are cloud-borne }\end{array}$ \\
DIAG1 & $\begin{array}{l}\text { In-cloud nucleation scavenging ratios diagnosed from cloud droplet and ice crystal number concentrations, } \\
\text { equating the mass with the number nucleation scavenging ratios, and using Hoose et al. (2008a,b) impaction }\end{array}$ \\
& scavenging kernels from Table 2 \\
DIAG2 & Same as DIAG1, but with separate mass and number nucleation scavenging ratios (see text for details) \\
DIAG-FULL & Same as DIAG2, but using physically detailed size-dependent in-cloud impaction scavenging coefficients, \\
& and kernels for cloud droplets and ice crystals shown in Figs. 1 and 2. \\
DIAG-FULL-noimp & Same as DIAG-FULL except no in-cloud impaction scavenging \\
PROG-AP & Prognostic stratiform aerosol processing scheme of Hoose et al. (2008a,b) \\
PROG-AP-noimp & Same as PROG-AP except no in-cloud impaction scavenging \\
\hline
\end{tabular}
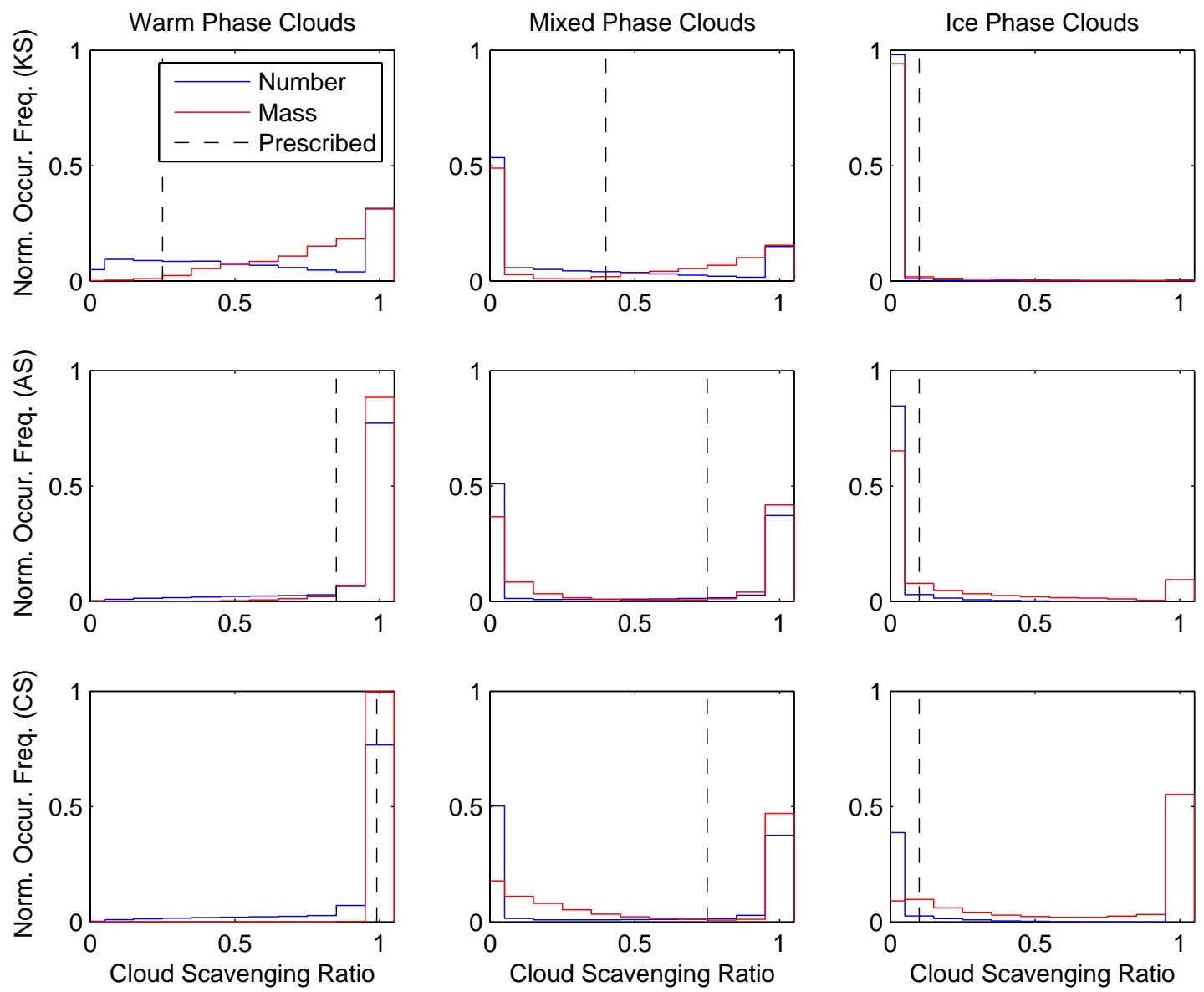

Fig. 3. Histograms of the frequency of occurrence of the stratiform in-cloud mass and number scavenging ratios for the simulation DIAGFULL (Table3), including both nucleation and size-dependent impaction scavenging for the internally mixed/soluble Aitken (KS), accumulation (AS), and coarse (CS) aerosol modes, and for warm $(T>273.15 \mathrm{~K})$, mixed $(238.15<T \leq 273.15 \mathrm{~K})$ and ice $(T \leq 238.15 \mathrm{~K})$ phase clouds. The dashed line indicates the prescribed ratios of Stier et al. (2005) used for the CTL simulation. 
considerable from the prescribed ratios, and are $<0.1$ for near to $50 \%$ of the occurrences for number scavenging. As the clouds glaciate, the Bergeron-Findeisen process causes rapid growth of the few ice crystals at the expense of the cloud droplets, which reduces the CDNC, and hence results in lower scavenged fractions for simulation DIAG-FULL. For warm phase clouds, the Aitken and accumulation mode scavenged fractions for simulation DIAG-FULL are greater than the prescribed ratios for $75 \%$ of the scavenging events. For ice clouds, the scavenging of the coarse mode is greater than the prescribed ratio of 0.1 for near to $60 \%$ of the scavenging occurrences, suggesting that the prescribed fraction for scavenging the coarse mode in ice clouds might be too low. Figure 3 also shows that the scavenged fractions for the mass distributions are higher than for the number distributions. This is physically correct since the median radii of the aerosol mass distributions are higher than for the respective number distributions, and so mass distributions should be scavenged with higher fractions. As opposed to equating the mass with the number scavenging ratios, our approach will alter the aerosol size distribution to produce smaller aerosols. The impact of in-cloud scavenging on aerosol size is examined further in the following subsection.

Figure 4 shows the zonal and annual mean aerosol mass scavenged into the cloud droplets and ice crystals averaged over clear and cloudy regions, comparing the simulations CTL, DIAG-FULL, and PROG-AP. The mass scavenged is greatest near the surface sources of the aerosols where warm phase clouds occur. In these regions, there are generally differences of $<10 \%$ for the DIAG-FULL relative to the CTL simulation, but there are reductions of up to $50 \%$ for sulfate and sea salt scavenged mass over the southern oceans. For the PROG-AP simulation, the mass scavenged for all aerosol species in the regions of warm clouds is lower by near to $50 \%$ compared to the CTL simulation. Hoose et al. (2008a) explained this is a result of the dependence of scavenged fraction on cloud history in an aerosol processing simulation. Alternatively, for the diagnostic and prescribed fraction scavenging approaches, all of the aerosol is assumed to be available for scavenging at each time-step since the in-droplet and in-crystal aerosol concentrations are not passed between model time-steps. Both the DIAG-FULL and PROG-AP simulation behave similarly in the colder regions of the troposphere where mixed and ice phase clouds occur. These more physically detailed parameterizations indicate that the mass scavenged, particularly in ice clouds, is greater by up to two-fold as compared to the mass scavenged using the prescribed scavenging fractions of the CTL simulation. This aerosol mass scavenged into the cloud droplets and ice crystals may not necessarily be removed by precipitation, since the rates of formation of precipitation, and the evaporation rates also ultimately control the aerosol mass that is removed from the atmosphere.

For the simulation PROG-AP, the mass transfer rates between the interstitial and in-droplet and in-crystal modes are shown in Fig. 5. This figure is similar to that shown in Hoose et al. (2008a). However, for this study we have used a more recent model version, and our dust and sea salt emissions are different with nudged meteorological conditions as compared to Hoose et al. (2008a). Similar to Hoose et al. (2008a), cloud droplet nucleation is a dominant process for transfer to aerosol mass into the in-droplet mode. Our results differ in that collisions are shown to dominate over nucleation or freezing for transfer of aerosol into the ice crystals. This is in agreement with recent work by Baumgardner et al. (2008), who suggested that impaction scavenging might dominate over nucleation scavenging for black carbon scavenging into ice crystals. Our study also implemented the below-cloud scavenging parameterization of Croft et al. (2009), which accounts for the higher aerosol removal by below-cloud scavenging in comparison to the results in Fig. 6 of Hoose et al. (2008a). Hoose et al. (2008a) implemented the prescribed below-cloud scavenging coefficients that are included in the standard ECHAM5-HAM model. Croft et al. (2009) show that the below-cloud scavenging with these prescribed coefficients is less vigorous than for the new physically detailed aerosol size-dependent parameterization of Croft et al. (2009). Sensitivity tests included in Hoose et al. (2008a) also show this same comparison, and find better agreement with observations for the detailed aerosol size-dependent parameterization of Croft et al. (2009).

\subsection{Impacts on predicted aerosol size}

Figure 6 shows the zonal and annual mean count median radius for the CTL simulation, and the percent difference for the simulations DIAG2 relative to DIAG1, and also for the simulations DIAG-FULL and PROG-AP relative to the CTL. As opposed to using the same nucleation scavenging ratios for the aerosol mass and number distributions (simulation DIAG1), the implementation of separate mass and number scavenging ratios gives annual and zonal mean soluble accumulation and coarse mode count median radii that are smaller by up to $40 \%$ and $50 \%$, respectively (simulation DIAG2). The regions of mixed and ice phase clouds in the middle and upper troposphere show the greatest sensitivity for the count median aerosol radius to the implementation of separate scavenging ratios for aerosol mass and number distributions. Thus, the implementation of separate mass and number nucleation scavenging ratios is worthwhile, particularly for mixed and ice phase clouds. This sensitivity is not as great for the near surface warm phase clouds since warm phase clouds had mass and number scavenging ratios of near to unity for the soluble/internally mixed accumulation and coarse modes in more than $90 \%$ of the scavenging occurrences (see Fig. 3). Figure 6 shows that the soluble/internally mixed Aitken mode radius does not change by more than $10 \%$ with the implementation of separate mass and number nucleation scavenging ratios. This lower sensitivity is expected since the number of occurrences of nucleation 
CTL S04 Scav. Mass $\left[\mathrm{g} \mathrm{m}^{-3}\right]$

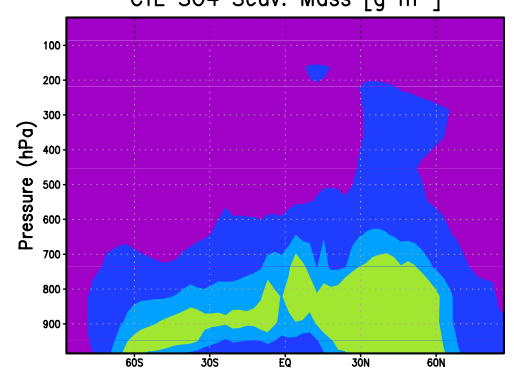

CTL BC Scav. Mass $\left[\mathrm{g} \mathrm{m}^{-3}\right]$

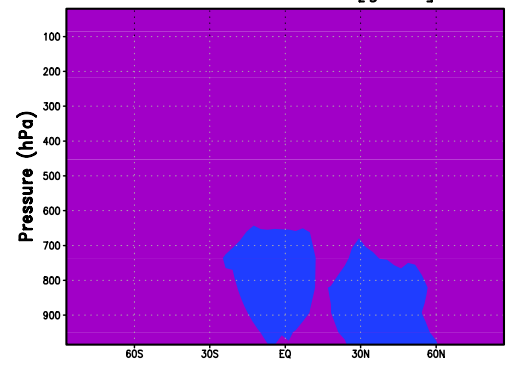

CTL POM Scav. Mass $\left[\mathrm{g} \mathrm{m}^{-3}\right]$
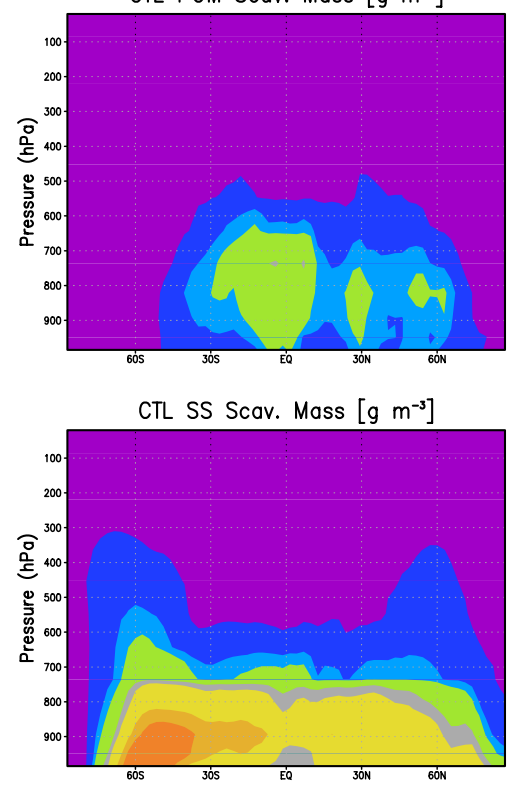

CTL DU Scav. Mass $\left[\mathrm{g} \mathrm{m}^{-3}\right]$

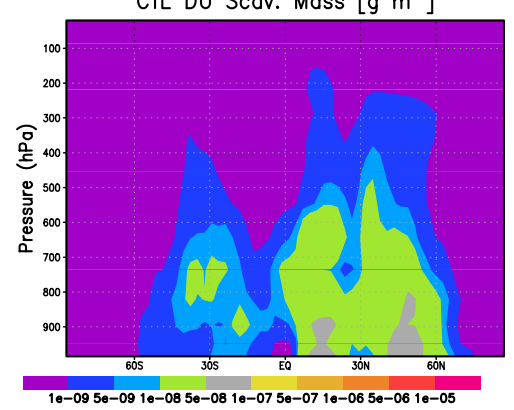

DIAG-FULL SO4 Change Scav. Mass vs CTL [\%. PROG-AP SO4 Change Scav. Mass vs CTL [\%]
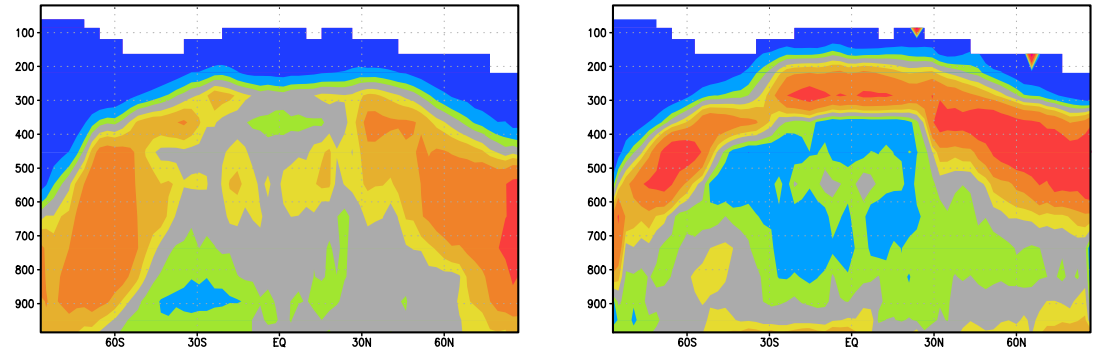

DIAG-FULL BC Change Scav. Mass vs CTL [\%]
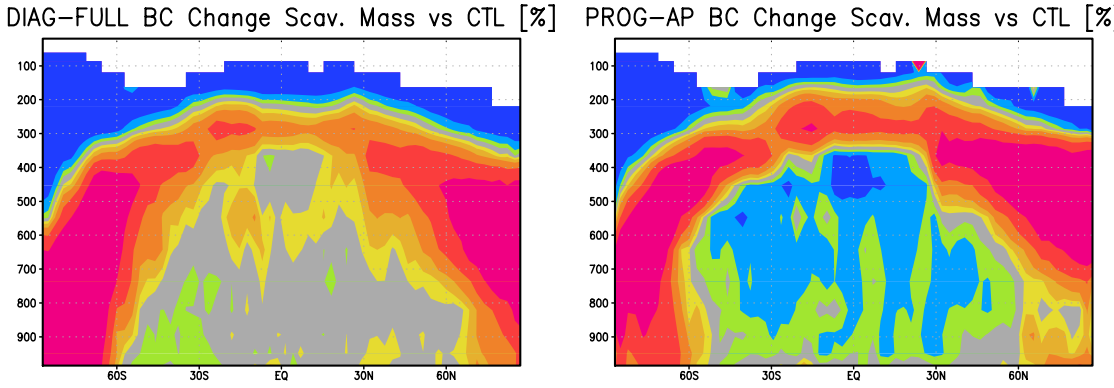

DIAG-FULL POM Change Scav. Mass vs CTL [\% PROG-AP POM Change Scav. Mass vs CTL [\%]
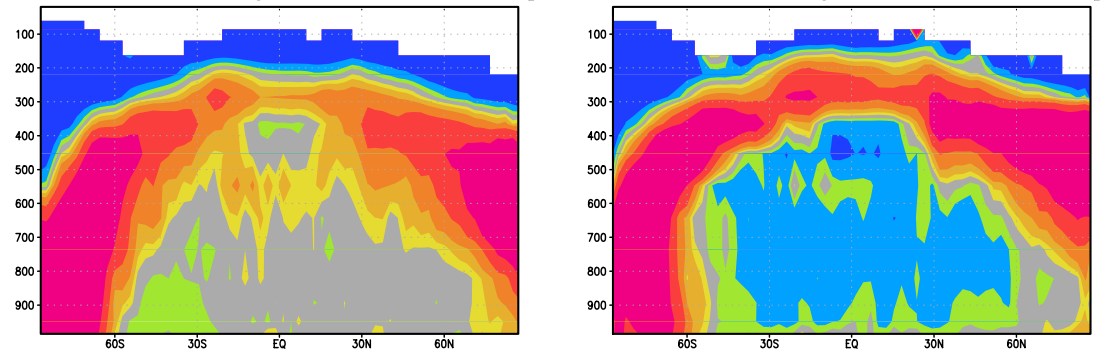

DIAG-FULL SS Change Scav. Mass vs CTL [\%]

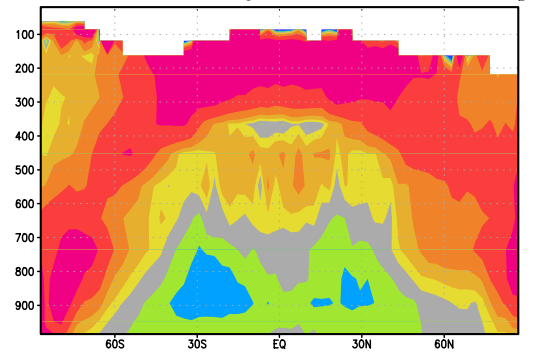

PROG-AP SS Change Scav. Mass vs CTL [\%]

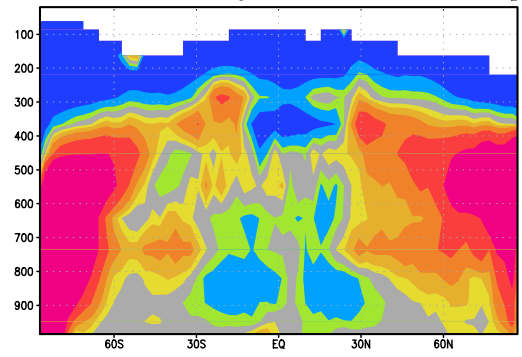

DIAG-FULL DU Change Scav. Mass vs CTL [\%]

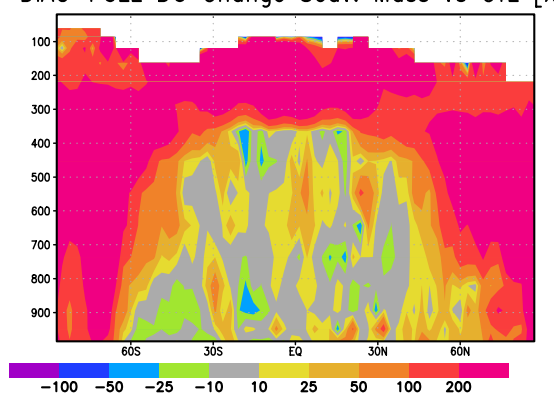

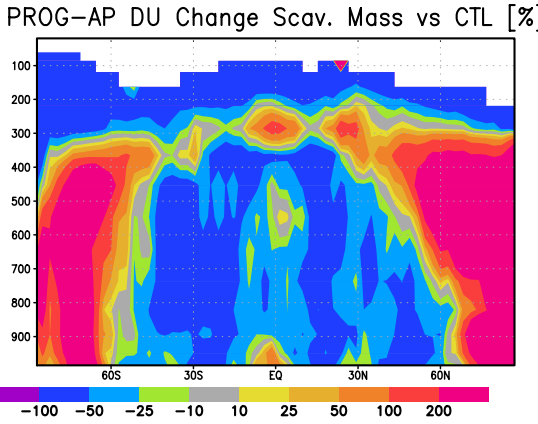

Fig. 4. Zonal and annual mean sulfate (SO4), black carbon (BC), particulate organic matter (POM), sea salt (SS), and dust (DU) mass $\left(\mathrm{g} \mathrm{m}^{-3}\right.$, except $\mathrm{g} \mathrm{S} \mathrm{m}^{-3}$ for sulfate) contained in cloud droplets and ice crystals for the simulation CTL and the percent change in these scavenged masses for the simulations DIAG-FULL and PROG-AP as compared to the CTL simulation. 

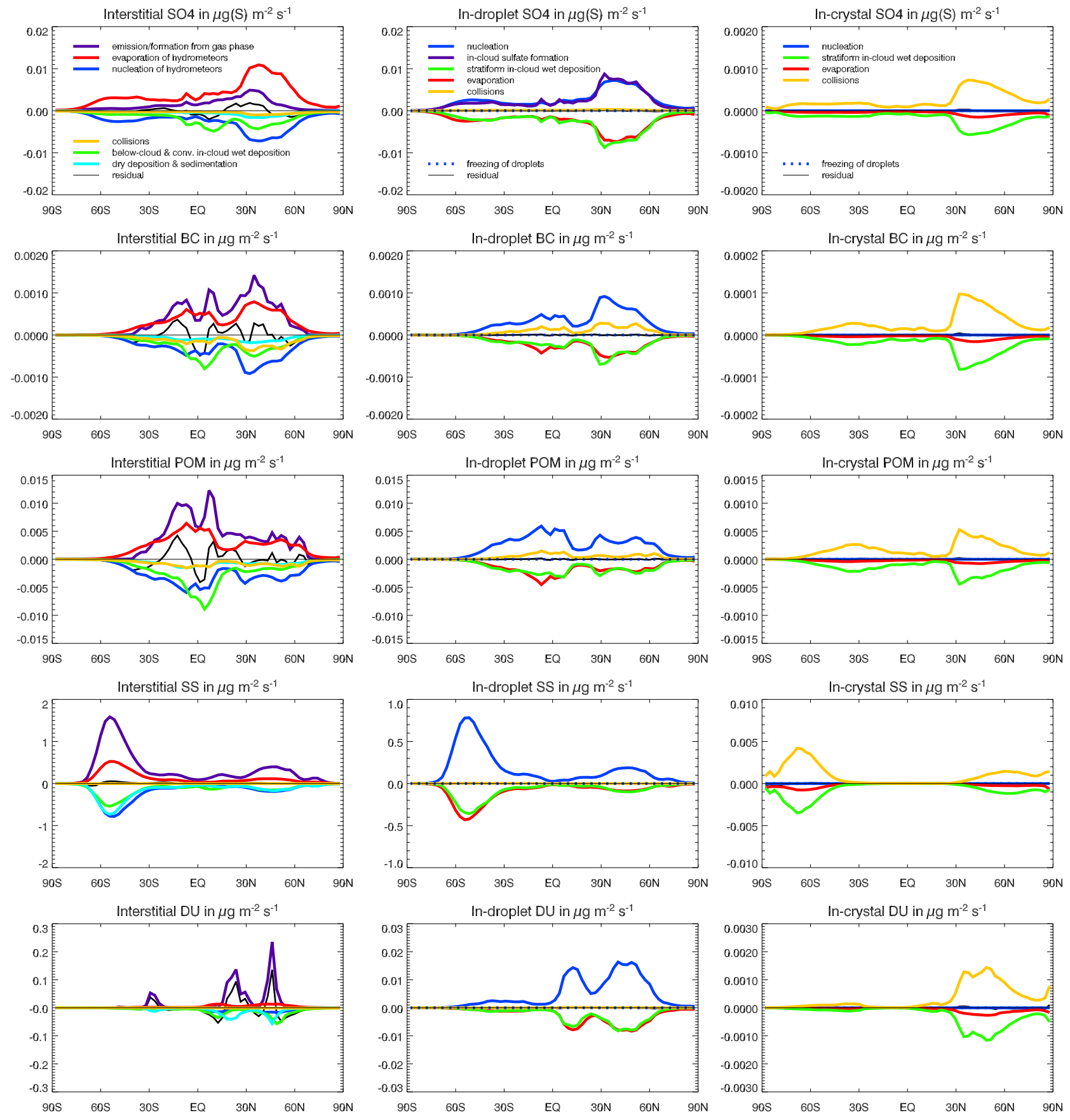

Fig. 5. The zonal and annual mean transfer rates $\left(\mu \mathrm{g} \mathrm{m}^{-2} \mathrm{~s}^{-1}\right.$, except $\mu \mathrm{g} \mathrm{S} \mathrm{m}{ }^{-2} \mathrm{~s}^{-1}$ for sulfate) between the interstitial, in-droplet and in-crystal aerosol modes for the simulation PROG-AP due to the processes of emission/formation from gas phase, droplet and ice crystal nucleation, droplet freezing, aerosol collisions with droplets and ice crystals, below-cloud and in-cloud wet deposition, dry deposition, and sedimentation.

scavenging for the soluble/internally mixed Aitken mode is nearly one order of magnitude smaller as compared to the larger soluble/internally mixed accumulation and coarse modes.
Figure 6 also shows how the zonal and annual mean count median radius is changed for the simulations DIAG-FULL and PROG-AP as compared to the CTL simulation. For the DIAG-FULL simulation, the zonal and annual mean soluble accumulation and coarse mode count median radii are 

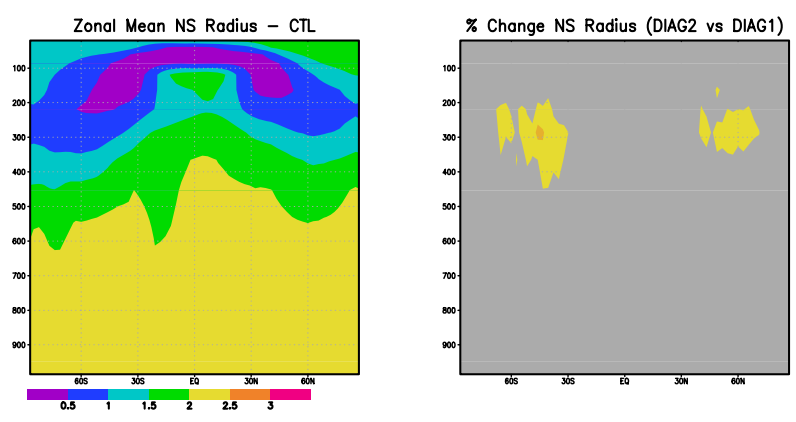

Zonal Mean KS Radius - CTL

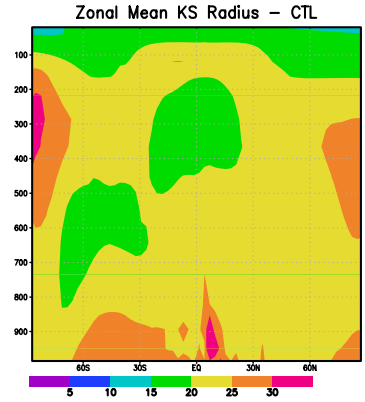

Zonal Mean AS Radius - CTL

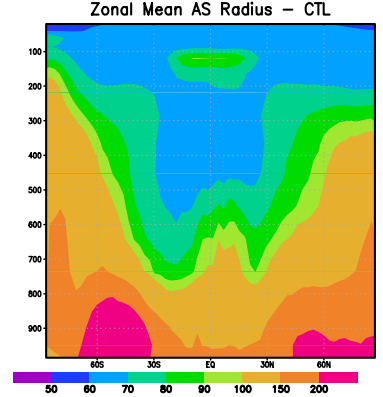

Zonal Mean CS Radius - CTL

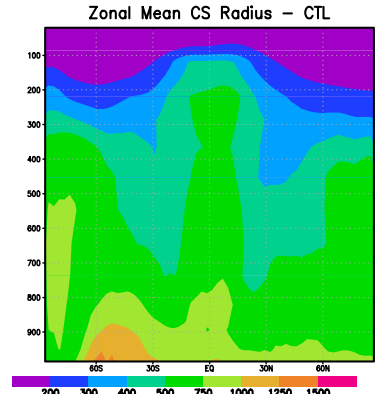

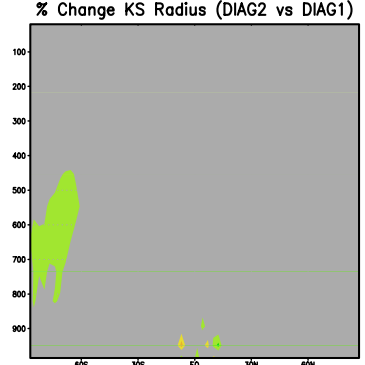

\% Change AS Radius (DIAG2 vs DIAG1)

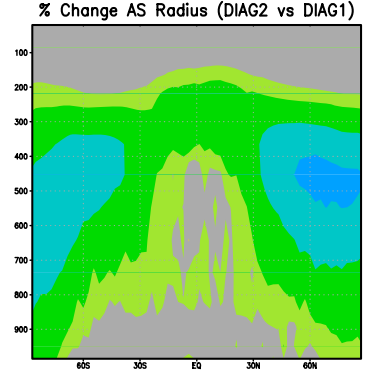

\% Change CS Radius (DIAG2 vs DIAG1)

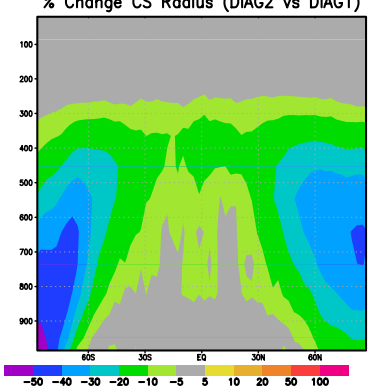

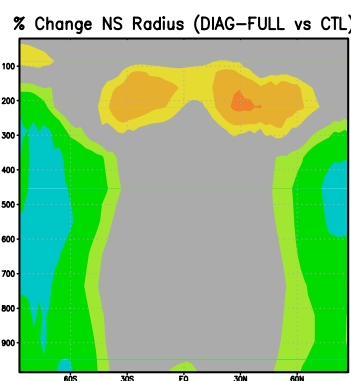
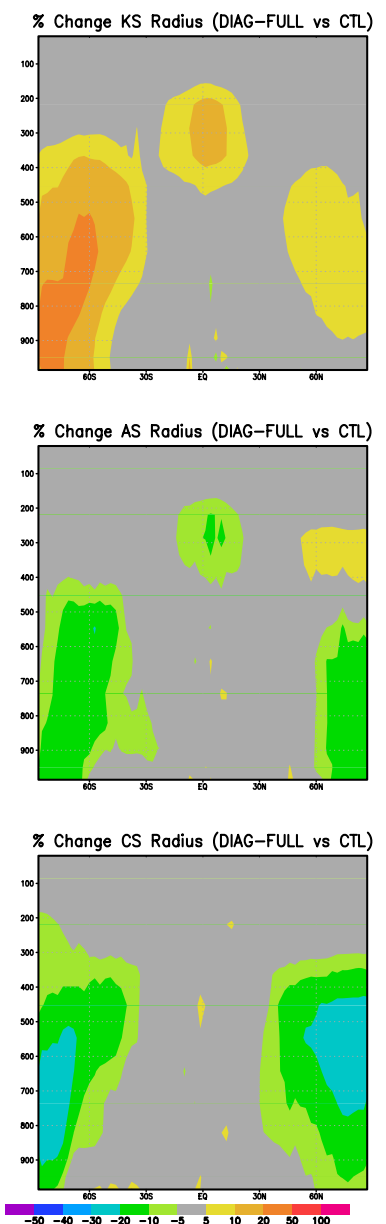
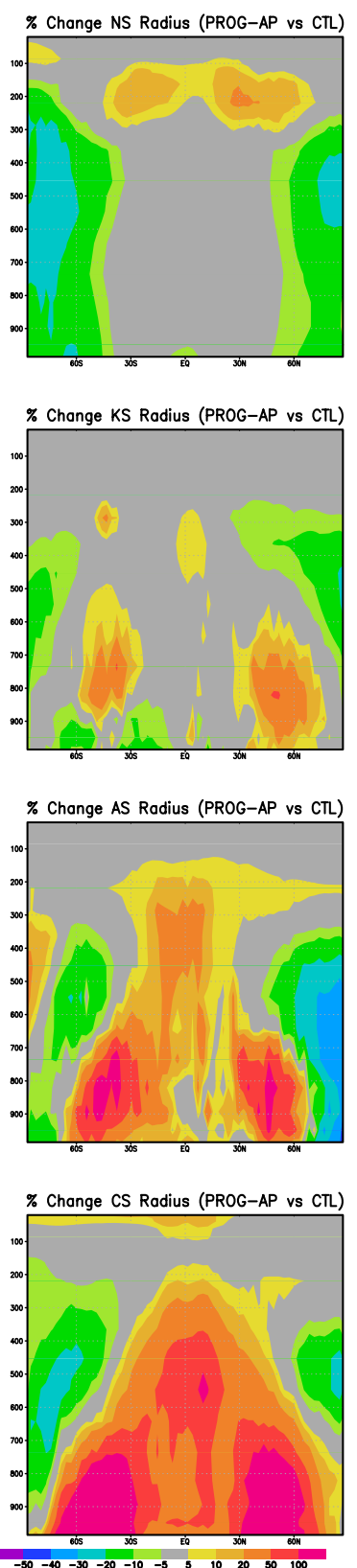

Fig. 6. Zonal and annual mean count median aerosol radius (nm) for the CTL simulation for the four soluble/internally mixed modes, nucleation (NS), Aitken (KS), accumulation (AS), and coarse (CS), and the percent change of the zonal and annual mean count median aerosol radius for the simulation DIAG2 relative to the simulation DIAG1, and for DIAG-FULL and PROG-AP simulations relative to the CTL simulation.

reduced by up to $50 \%$ in regions of mixed and ice phase clouds, but the soluble Aitken mode radius is increased by up to $30 \%$. Conversely, for the PROG-AP simulation the zonal and annual soluble accumulation and coarse mode radii are increased by near to $100 \%$ throughout much of the lower and middle troposphere. This increased radius is typical for prognostic aerosol cloud processing simulations, which include the process of coagulation of in-droplet and in-crystal aerosols followed by evaporation or sublimation. This is associated with the release of larger aerosol particles to the atmosphere (Hoose et al., 2008a).

\subsection{Impacts on predicted aerosol mass}

The zonal and annual mean aerosol mass mixing ratios comparing the simulations CTL, DIAG-FULL and PROG-AP are shown in Fig. 7. In comparison to the CTL simulation, both 


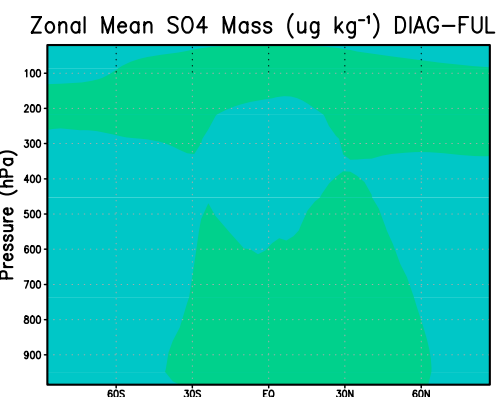

Zonal Mean BC Mass (ug $\mathrm{kg}^{-1}$ ) DIAG-FULL

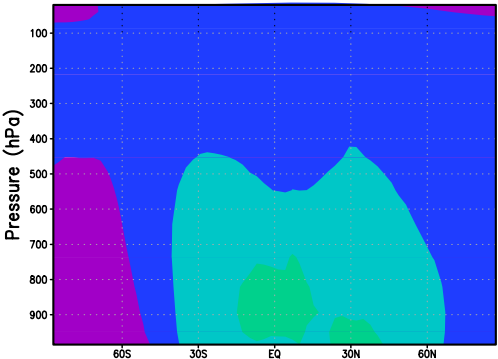

Zonal Mean POM Mass (ug kg ${ }^{-1}$ ) DIAG-FULL

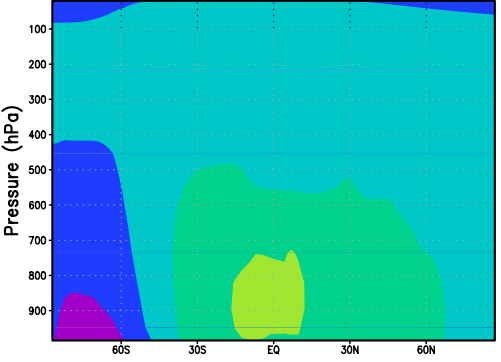

Zonal Mean SS Mass (ug kg-1) DIAG-FULL

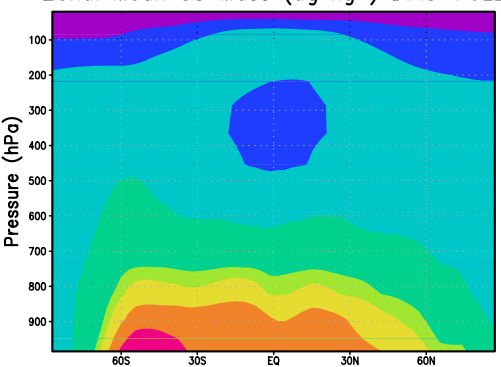

Zonal Mean Dust Mass (ug kg $\mathrm{kg}^{-1}$ DIAG-FULL

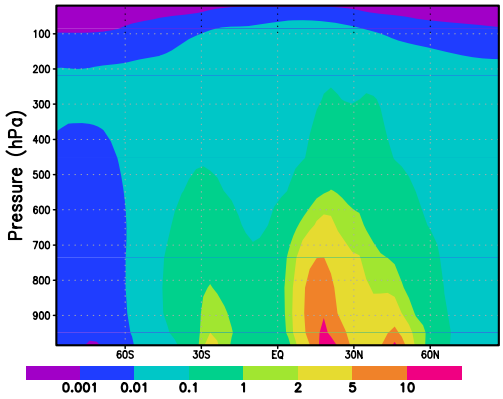

\% Change S04 Mass (DIAG-FULL vs. CTL)

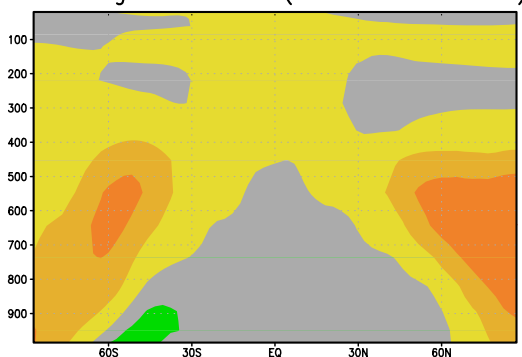

\% Change BC Mass (DIAG-FULL vs. CTL)

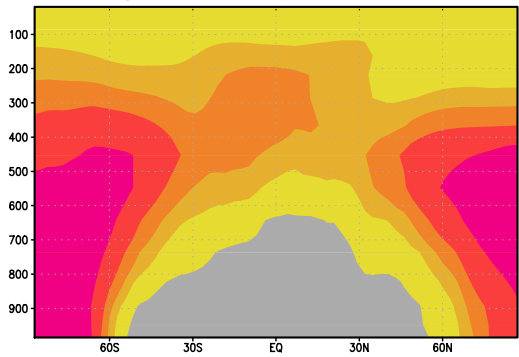

\% Change POM Mass (DIAG-FULL vs. CTL)

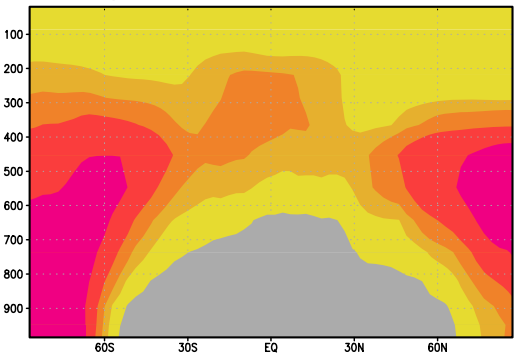

\% Change SS Mass (DIAG-FULL vs. CTL)

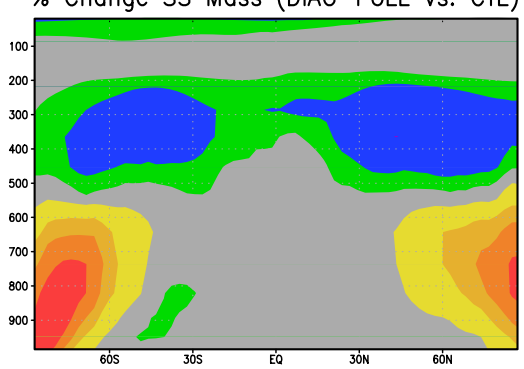

\% Change Dust Mass (DIAG-FULL vs. CTL)

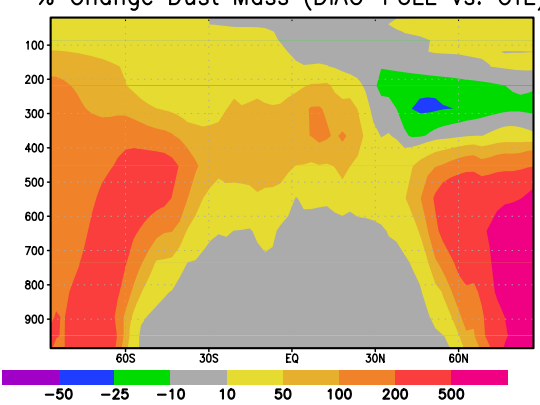

\% Change SO4 Mass (PROG-AP vs. CTL)

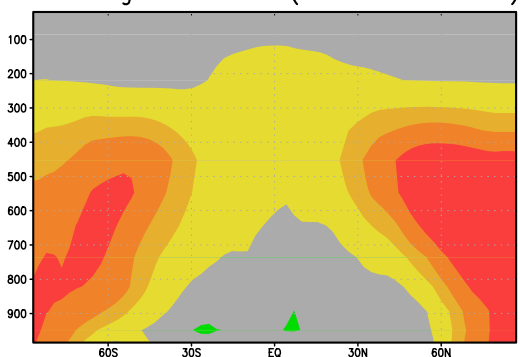

\% Change BC Mass (PROG-AP vs. CTL)

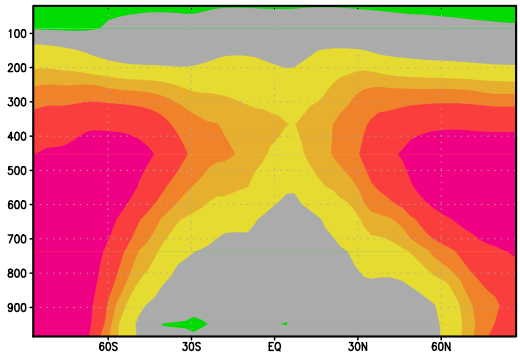

\% Change POM Mass (PROG-AP vs. CTL)

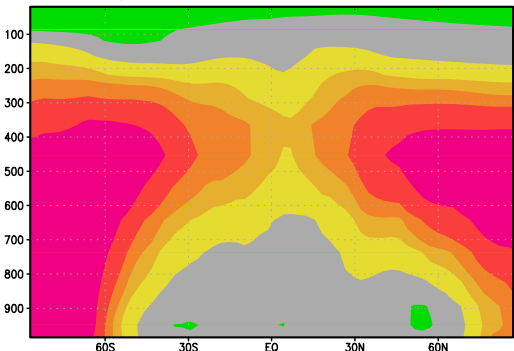

\% Change SS Mass (PROG-AP vs. CTL)

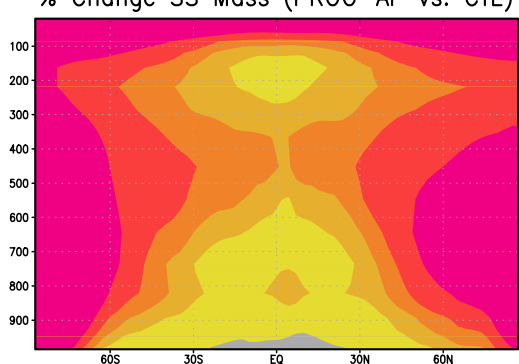

\% Change Dust Mass (PROG-AP vs. CTL)

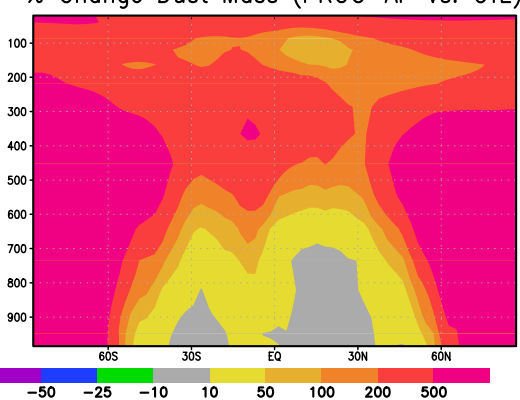

Fig. 7. The zonal and annual mean sulfate (SO4), black carbon (BC), particulate organic matter (POM), sea salt (SS), and dust (DU) mass mixing ratios $\left(\mu \mathrm{g} \mathrm{kg}^{-1}\right.$, except $\mu \mathrm{g} \mathrm{sk}^{-1}$ for sulfate) for the simulation DIAG-FULL and the percent change in these masses for the simulations DIAG-FULL and PROG-AP as compared to the simulation CTL. 
Table 4. Annual and global mean mass burdens ( $\mathrm{Tg}$, except $\mathrm{Tg} \mathrm{S}$ for sulfate) and lifetimes (days) given in brackets immediately following the burdens, for the five aerosol species, and for the simulations described in Table 3. POM refers to particulate organic matter.

\begin{tabular}{lccccc}
\hline Burden (Lifetime) & Sulfate & Black Carbon & POM & Dust & Sea Salt \\
\hline CTL & $0.843(4.2)$ & $0.119(5.6)$ & $1.04(5.7)$ & $3.60(3.9)$ & $8.28(0.56)$ \\
F100 & $0.749(3.7)$ & $0.109(5.2)$ & $0.99(5.4)$ & $3.40(3.7)$ & $7.86(0.53)$ \\
F100-INT & $0.750(3.7)$ & $0.116(5.5)$ & $1.10(6.1)$ & $3.77(4.1)$ & $7.85(0.53)$ \\
DIAG1 & $0.965(4.8)$ & $0.133(6.3)$ & $1.17(6.5)$ & $4.10(4.3)$ & $8.39(0.57)$ \\
DIAG2 & $0.867(4.3)$ & $0.122(5.8)$ & $1.08(6.0)$ & $3.93(4.2)$ & $7.99(0.54)$ \\
DIAG-FULL & $0.886(4.4)$ & $0.132(6.3)$ & $1.11(6.1)$ & $3.69(3.9)$ & $7.95(0.54)$ \\
DIAG-FULL-noimp & $0.991(4.6)$ & $0.135(6.4)$ & $1.13(6.2)$ & $3.95(4.2)$ & $8.01(0.54)$ \\
PROG-AP & $0.952(4.8)$ & $0.129(6.1)$ & $1.13(6.2)$ & $4.41(4.6)$ & $11.4(0.77)$ \\
PROG-AP-noimp & $1.228(6.1)$ & $0.186(8.8)$ & $1.46(8.1)$ & $4.78(5.0)$ & $12.9(0.87)$ \\
\hline
\end{tabular}

the DIAG-FULL and the PROG-AP simulations show an increase in dust and carbonaceous aerosol mass mixing ratios by more than five-fold, and up to two-fold for sea salt and sulfate near the middle troposphere, and towards the poles where mixed phase and ice clouds occur. Dust and carbonaceous aerosols exist partly in the insoluble modes, which are not scavenged by nucleation processes. Differences in the parameterization of impaction scavenging has a greater influence on these species. It is not intuitive whether an increase to the scavenged mass (shown in Fig. 4) should be associated with an increase or a decrease in the respective mass mixing ratio for any given aerosol species since there are a variety of processes, including rates of scavenging at other altitudes, evaporation, precipitation removal and transport, which interact to ultimately control the mass mixing ratio. Figure 4 shows that the scavenged mass was increased for all aerosol species towards the upper troposphere, but the sea salt mass mixing ratios in the upper troposphere are decreased by up to $50 \%$, whereas for the other aerosol species, the mass mixing ratios were increased at these altitudes.

Table 4 presents the annual and global mean mass burdens and lifetimes for the five aerosol species, and for all the simulations conducted. The aerosol mass burdens are lower for the simulation DIAG-FULL, by $7 \%, 2 \%, 16 \%$, and $30 \%$ for sulfate, particulate organic matter, dust, and sea salt, respectively, as compared to the PROG-AP simulation. Similarly, Ghan and Easter (2006) showed that a diagnostic scavenging scheme under-estimated aerosol burdens by near to $20 \%$ as compared to a prognostic treatment of in-droplet aerosol. Aerosols are kept within the cloud droplets and ice crystals between time-steps for the prognostic aerosol processing simulation, and this affects the mass and number of aerosols available for scavenging into the cloud droplets and crystals at each time-step, and ultimately the mass distribution.

The simulation F100 allows us to compare the prescribed ratio approach of Stier et al. (2005) with the simplistic assumption that $100 \%$ of the aerosols in clouds are in the droplets and crystals. This simplistic approach has been used in global models (Barth et al., 2000). We find that the global and annual mean aerosol mass burdens in simulation F100 are lower in comparison to the CTL simulation, by up to $10 \%$ for sulfate. The greatest mass burden difference between all simulations was $32 \%$ for the global and annual mean sea salt burden, between the F100 simulation and the PROGAP simulations. Assuming that only the soluble/internally mixed aerosols are cloud-borne for the simulation F100-INT as compared to F100 does not affect the sulfate and sea salt burdens significantly, since these aerosols do not exist in the insoluble modes. However, the annual and global mean black carbon and dust burdens are higher by near to $10 \%$ when none of the insoluble aerosols are allowed to be cloud-borne.

Comparing the simulations DIAG1 and DIAG2 illustrates the impact of diagnosing separate stratiform nucleation scavenging ratios for aerosol mass and number distributions. The global and annual mean mass burdens are higher by near to $10 \%$ and $8 \%$ for sulfate and carbonaceous aerosols, and 5\% for sea salt and dust for the simulation DIAG1 as compared to DIAG2, which diagnoses separate mass and number scavenging ratios. Thus, particularly for sulfate, diagnosing separate mass and number nucleation scavenging ratios is of importance.

Table 4 also includes two simulations with the in-cloud impaction processes turned off, DIAG-FULL-noimp and PROG-AP-noimp. In comparing these two simulations with DIAG-FULL and PROG-AP, respectively, impaction scavenging is found to have a greater influence on the mass burdens for the aerosol species that occur in the submicron size modes (sulfate and carbonaceous aerosols), and for the prognostic simulations. Impaction scavenging is particularly relevant for black carbon, which has a significant mass fraction in the insoluble Aitken mode, which is not scavenged by nucleation processes. The annual and global mean sulfate, particulate organic matter, and black carbon mass burdens were reduced by $22 \%, 23 \%$, and $30 \%$, respectively, for the PROG-AP simulation as compared to PROG-AP-noimp. When the in-droplet and in-crystal aerosol concentrations are 
treated prognostically, impaction has a greater effect on the predicted burdens since impaction continues to add aerosols to the existing in-droplet and in-crystal concentrations over successive time-steps, unlike for DIAG-FULL simulation. To further examine the relevance of the impaction parameterization, Sect. 4 will present a comparison of model predictions of black carbon vertical profiles with observations.

\subsection{Impacts on predicted aerosol number}

Figure 8 shows the geographic distribution of the ratio of the number burdens between the F100, DIAG-FULL, and PROG-AP simulations, and the CTL simulation. For the PROG-AP simulation only the interstitial number burdens are shown. The accumulation mode number burdens in the DIAG-FULL and PROG-AP simulations increase by near to 2 and 5 times, respectively, as compared to the CTL in the regions of greater stratiform cloud cover, poleward of $30^{\circ}$. Ghan and Easter (2006) also found accumulation mode number burdens higher by up to two times towards the poles for a prognostic as compared to diagnostic in-cloud aerosol scavenging treatment. For the F100 simulation, the accumulation mode number burdens are lower by up to $20 \%$ over the regions of stratiform cloud cover in comparison to the CTL simulation. However, for the F100 simulation, the nucleation number burdens are significantly increased by up to five times over the polar regions in comparison to the CTL simulation. Despite the increased in-cloud scavenging coefficients used in F100, the reduction in surface area available for sulfate condensation on to the larger aerosol modes leads to an increase in new particle formation. The annual and global mean new particle nucleation rate was nearly three times greater for the F100 simulation as compared to the DIAG-FULL simulation. For the PROG-AP simulation, the interstitial coarse mode is reduced by up to half over the southern oceans. This occurs since the in-droplet and incrystal modes (not shown here) contain these aerosols.

Table 5 summarizes the global and annual mean number burdens for the seven standard modes of the ECHAM5HAM. The accumulation mode number burden is increased by near to $30 \%$ and $50 \%$ for the DIAG-FULL and PROGAP simulations, respectively, relative to the CTL simulation. Ghan and Easter (2006) showed that smaller changes in global aerosol burdens (near to 20\%) changed the magnitude of the direct and indirect radiative forcing of aerosols on climate by considerably less than the magnitude of the current uncertainty associated with these forcings. However, since we find greater changes to the aerosol number burdens, future work should address the impact of changes of this magnitude on the direct and indirect aerosol effects predicted by our model. Comparing the number burdens for the PROGAP and PROG-AP-noimp simulations illustrates the importance of the impaction parameterization in a global model. Without any impaction scavenging for the PROG-AP-noimp simulation, the global, annual mean accumulation number is increased by near to $60 \%$. As a consquence of this increased surface area, the number of nucleation mode particles is halved. The F100 simulation has a nucleation mode number burden that is nearly double that for the DIAG-FULL simulation since the surface area available for condensation on to the larger modes is reduced. Since the F100 simulation had more vigourous scavenging, the accumulation mode number is nearly $30 \%$ less for the F100 simulation relative to DIAG-FULL. A complete examination of the impacts of this enhanced new particle formation on modeled radiation and chemistry is beyond the scope of this paper, but should be examined in future studies. This excessive fine mode particle production in response to enhanced scavenging is of additional relevance from an air quality perspective.

\subsection{Impacts on predicted aerosol wet deposition}

The geographic distribution of wet deposition for the five aerosol species is shown in Fig. 9. For the species that exist only in the soluble/internally mixed modes, sea salt and sulfate, there is very little change to the geographic distribution of wet deposition for the DIAG-FULL simulation as compared to the CTL. For the DIAG-FULL simulation, dust and the carbonaceous aerosol wet deposition is generally changed by less than $10 \%$ close to the major source regions, but increases poleward and over the more remote oceans by near to $100 \%$. Over these more remote regions, these aerosols will have aged into the soluble/internally mixed modes, which are scavenged by cloud droplet and ice nucleation. However, the magnitude of the wet deposition is quite small in these regions. For the PROG-AP simulation, there are reductions in the wet deposition of sulfate and carbonaceous aerosols up to $25 \%$ close to the source regions. The total precipitation, which is also shown in Fig. 9 does not change significantly between simulations, and so these differences in wet deposition occur in response to the changes to the in-cloud scavenging parameterization, as opposed to changes to the rate of precipitation.

\subsubsection{Aerosol mass deposition budgets}

Tables 6-10 summarize the deposition budgets for the five aerosol species. The simulation DIAG-FULL shows that aerosol mass removal by stratiform in-cloud scavenging is primarily by nucleation as opposed to impaction processes. Nucleation scavenging accounts for $98 \%, 94 \%, 96 \%, 51 \%$, and $99 \%$ of the total deposition due to stratiform in-cloud scavenging for sulfate, black carbon, particulate organic matter, dust, and sea salt, respectively. The remainder is due to in-cloud impaction scavenging. Below-cloud scavenging accounts for $13 \%, 14 \%, 11 \%, 25 \%$, and $23 \%$ of the total annual and global mean deposition of sulfate, black carbon, particulate organic matter, dust, and sea salt, respectively for the simulation DIAG-FULL. For the DIAG-FULL simulation, in-cloud scavenging accounts for near to $80 \%$ of the total 
Table 5. Global and annual mean number burdens $\left(10^{10} \mathrm{~m}^{-2}\right)$ for the nine simulations and for the seven aerosol modes. CD and IC refer to the in-droplet and in-crystal modes of the prognostic simulation. Abbreviations are defined in Tables 1 and 3.

\begin{tabular}{lccccccccc}
\hline Number & NS & KS & AS & CS & KI & AI & CI & CD & IC \\
\hline CTL & 18800. & 870. & 75.1 & 0.441 & 8.29 & 0.031 & 0.068 & & \\
F100 & 31500. & 1170. & 65.9 & 0.414 & 6.84 & 0.028 & 0.063 & & \\
F100-INT & 31500. & 1160. & 67.0 & 0.430 & 8.69 & 0.047 & 0.081 & & \\
DIAG1 & 17600. & 668. & 87.2 & 0.476 & 8.12 & 0.054 & 0.089 & & \\
DIAG2 & 18700. & 737. & 88.9 & 0.483 & 8.03 & 0.052 & 0.088 & & \\
DIAG-FULL & 16700. & 610. & 94.2 & 0.470 & 9.21 & 0.047 & 0.083 & & \\
DIAG-FULL-noimp & 15300. & 604. & 98.6 & 0.483 & 10.0 & 0.056 & 0.090 & & \\
PROG-AP & 22500. & 726. & 115. & 0.366 & 6.11 & 0.055 & 0.099 & 5.65 & 0.457 \\
PROG-AP-noimp & 10500. & 605. & 179. & 0.375 & 11.2 & 0.069 & 0.116 & 10.5 & 0.683 \\
\hline
\end{tabular}

Table 6. Annual mean deposition of sulfate $\left(\mathrm{Tg} \mathrm{S} \mathrm{yr}^{-1}\right)$ due to the processes of in-cloud nucleation and impaction scavenging for warm $(T>273.15 \mathrm{~K})$, mixed $(238.15<T \leq 273.15 \mathrm{~K})$ and ice phase $(T \leq 238.15 \mathrm{~K})$ stratiform clouds, combined nucleation and impaction scavenging for warm, mixed, and ice phase convective clouds, total in-cloud scavenging (ICS), below-cloud scavenging (BCS), dry deposition, and sedimentation.

\begin{tabular}{lccccccc}
\hline Sulfate & CTL & F100 & F100-INT & DIAG1 & DIAG2 & DIAG-FULL & PROG-AP \\
\hline Stratiform clouds & & & & & & & \\
Warm nucleation & $23.7^{*}$ & $24.6^{*}$ & $24.7^{*}$ & 23.6 & 24.6 & 24.4 & $18.9^{*}$ \\
Mixed nucleation & $13.8^{*}$ & $14.1^{*}$ & $14.2^{*}$ & 10.9 & 12.2 & 12.1 & $8.21^{*}$ \\
Ice nucleation & $0.171^{*}$ & $0.388^{*}$ & $0.388^{*}$ & 0.544 & 0.420 & 0.444 & $0.624^{*}$ \\
Warm impaction & & & & 0.256 & 0.119 & 0.265 & \\
Mixed impaction & & & & 0.364 & 0.255 & 0.392 & \\
Ice impaction & & & & 0.093 & 0.079 & 0.005 & \\
\hline Convective clouds & & & & & & & \\
Warm & 9.33 & 9.02 & 9.02 & 9.33 & 9.11 & 9.06 & 8.26 \\
Mixed & 12.4 & 12.0 & 12.0 & 12.9 & 12.3 & 12.4 & 11.2 \\
Ice & 0.72 & 0.70 & 0.70 & 0.78 & 0.73 & 0.77 & 0.70 \\
\hline Total ICS & 60.1 & 60.8 & 61.0 & 58.8 & 59.8 & 59.9 & 48.0 \\
Total BCS & 9.67 & 8.96 & 8.91 & 10.9 & 9.97 & 9.91 & 14.9 \\
Dry Deposition & 2.02 & 2.00 & 1.98 & 1.94 & 1.91 & 1.89 & 3.72 \\
Sedimentation & 1.22 & 1.32 & 1.24 & 1.10 & 1.06 & 1.04 & 6.11 \\
\hline
\end{tabular}

* Indicates that stratiform nucleation and impaction are included together in the result shown for stratiform nucleation.

removal of sulfate and carbonaceous aerosols, and close to $35 \%$ of the total removal of sea salt and dust. Stratiform, as opposed to convective, in-cloud scavenging accounts for near to $65 \%$ of the total removal of sea salt and sulfate, but nearer to $40 \%$ of the total removal of carbonaceous aerosols and dust, which have greater sources towards the tropics. Removal by warm phase nucleation (temperatures $>273.15 \mathrm{~K}$ ) is about twice that of mixed phase nucleation (temperatures between $273.15 \mathrm{~K}$ and $238.15 \mathrm{~K}$ ) for sulfate and the carbonaceous aerosols, whereas for sea salt and dust these processes are nearly equivalent.

Differences to the parameterization of the impaction scavenging process between simulations DIAG2 and DIAGFULL, increased the annual and global mean dust and sea salt removal by impaction by near to 2 orders of magnitude for the simulation DIAG-FULL. For black carbon, and particulate organic matter, the impaction scavenging is reduced by about half in DIAG-FULL as compared to DIAG2. However, since global and annual mean aerosol mass removal is not primarily attributed to stratiform impaction processes, the global and annual mean mass burdens (see Table 4) change by less than $10 \%$ for all aerosol species between simulation DIAG-FULL and DIAG2.

For the simulation PROG-AP compared to the CTL simulation, the total aerosol removal by in-cloud scavenging is reduced by 20 to $25 \%$ for all aerosol species, with the greatest changes for sulfate and sea salt, with a sea salt mass burden increase of $35 \%$. Evaporation releases considerable aerosol 

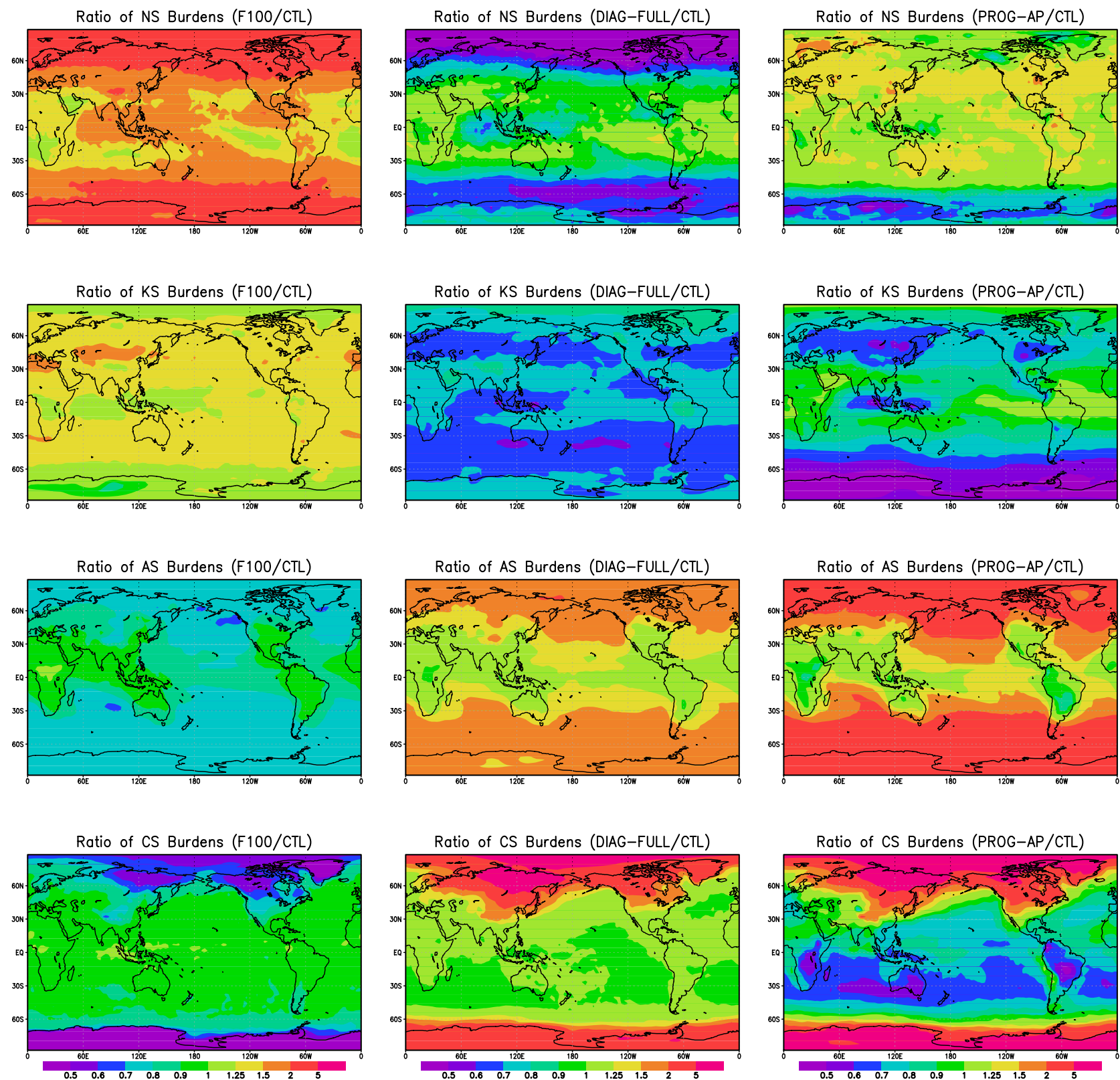

Fig. 8. The geographic distribution of the ratio of the vertically integrated number burdens for the four soluble/internally mixed modes nucleation (NS), Aitken (KS), accumulation (AS), and coarse (CS) - for the simulations F100, DIAG-FULL, and PROG-AP as compared to the CTL simulation. For the PROG-AP simulation, these are interstitial mode number burdens only.

mass back to the atmosphere for the PROG-AP simulation. Increased aerosol burden for prognostic aerosol cloud processing simulations has been shown by Hoose et al. (2008a) and Ghan and Easter (2006). The aerosol load that remains in the stratiform cloud droplets is not available for the convective scavenging, and so the convective in-cloud scavenging is also reduced by near to $10 \%$ for sulfate. Only dust is affected in the opposite sense and the convective scavenging is actually increased by a few percent. This is expected since stratiform in-cloud scavenging of dust is a less important sink compared to other removal processes, and Fig. 1 shows that the Hoose et al. (2008a,b) impaction scheme also scavenges coarse mode particles, such as dust, into the cloud droplets relatively inefficiently. These results point to the relevance of developing a convective aerosol processing treatment in the future that should be coupled with the stratiform aerosol processing treatment of Hoose et al. (2008a,b). 

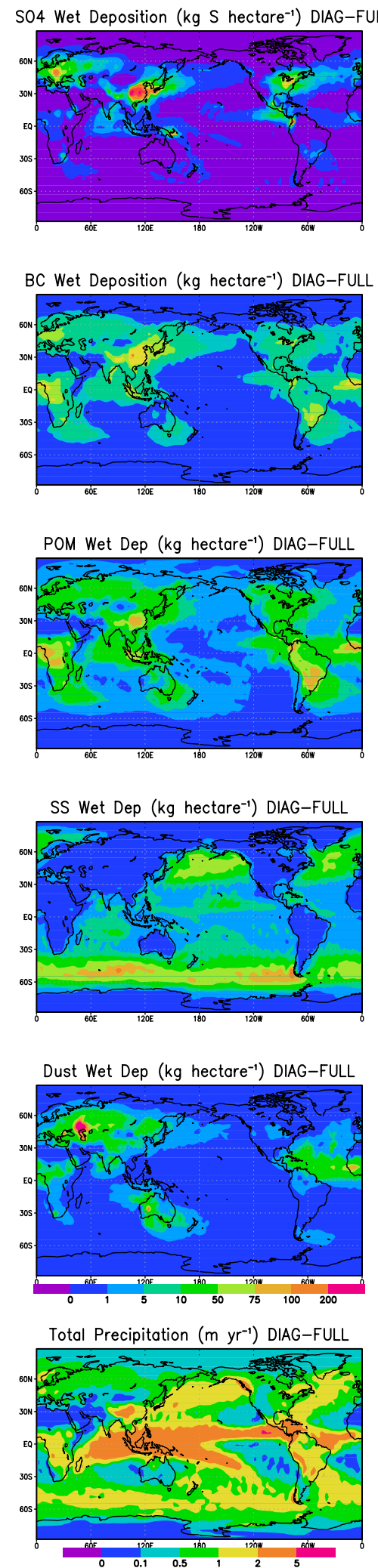
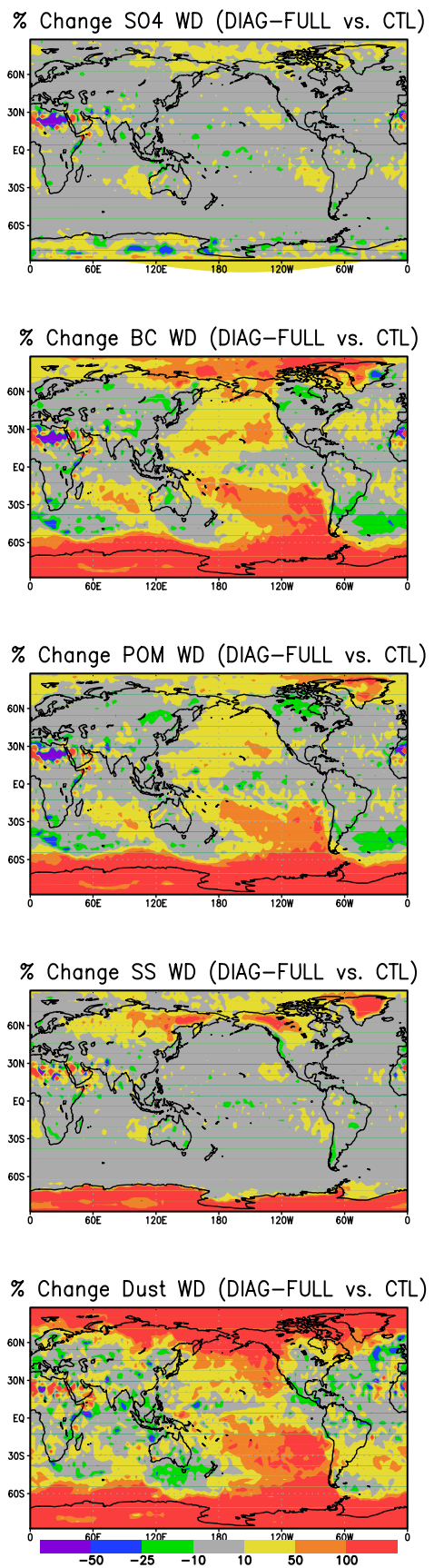

\% Change Precipitation (DIAG-FULL vs. CTL)

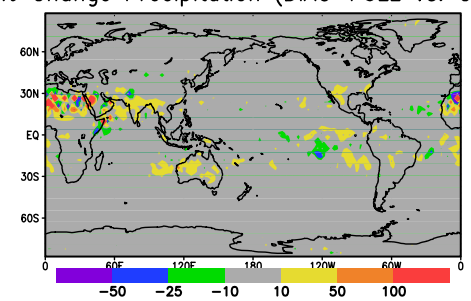

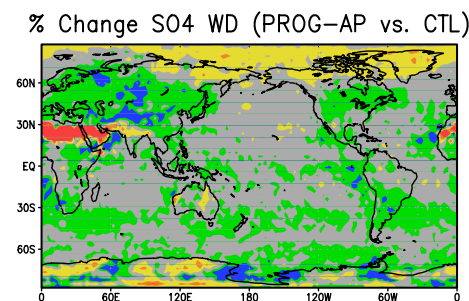

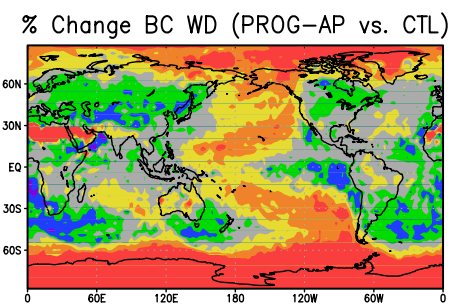

\% Change POM WD (PROG-AP vs. CTL)
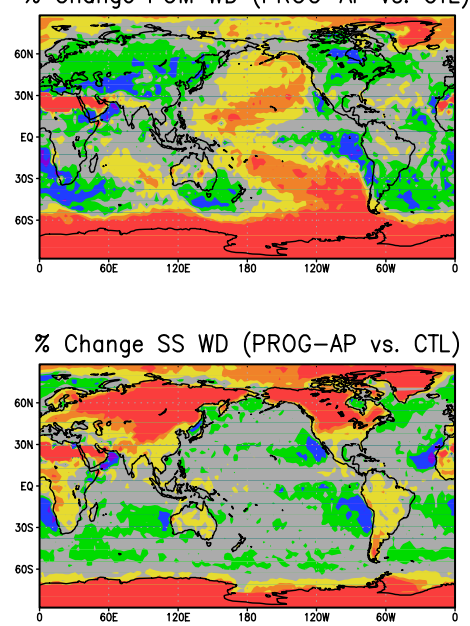

\% Change Dust WD (PROG-AP vs. CTL)

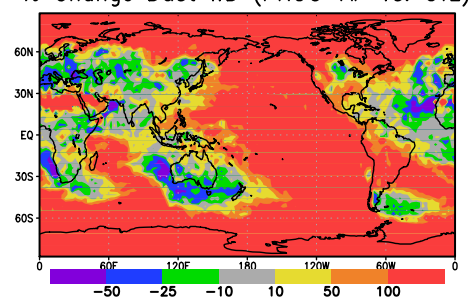

\% Change Precipitation (PROG-AP vs. CTL)

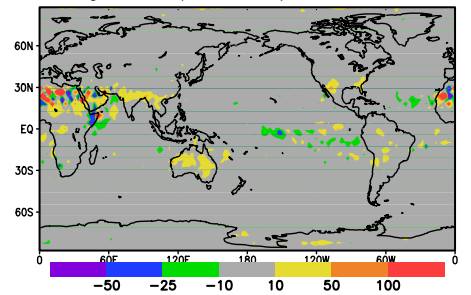

Fig. 9. The geographic distribution of sulfate (SO4), black carbon (BC), particulate organic matter (POM), sea salt (SS) and dust annual mean wet deposition $\left(\mathrm{kg} \mathrm{ha}^{-1}\right.$, except $\mathrm{kg} \mathrm{Sha}^{-1}$ for sulfate), and total annual precipitation $(\mathrm{m})$ for the DIAG-FULL simulation, and the percent change for the simulations DIAG-FULL and PROG-AP as compared to the CTL simulation. 
Table 7. Similar to Table 6 except for black carbon deposition $\left(\mathrm{Tg} \mathrm{yr}^{-1}\right)$.

\begin{tabular}{lccccccc}
\hline Black Carbon & CTL & F100 & F100-INT & DIAG1 & DIAG2 & DIAG-FULL & PROG-AP \\
\hline Stratiform clouds & & & & & & & \\
Warm nucleation & $1.86^{*}$ & $2.10^{*}$ & $1.86^{*}$ & 1.49 & 1.61 & 1.75 & $1.39^{*}$ \\
Mixed nucleation & $1.16^{*}$ & $1.14^{*}$ & $1.17^{*}$ & 0.635 & 0.766 & 0.861 & $0.582^{*}$ \\
Ice nucleation & $0.014^{*}$ & $0.017^{*}$ & $0.031^{*}$ & 0.055 & 0.039 & 0.052 & $0.073^{*}$ \\
Warm impaction & & & & 0.439 & 0.413 & 0.088 & \\
Mixed impaction & & & & 0.217 & 0.197 & 0.081 & \\
Ice impaction & & & & 0.012 & 0.009 & 0.001 & \\
\hline Convective clouds & & & & & & & 1.04 \\
Warm & 1.04 & 1.00 & 1.03 & 1.06 & 1.03 & 1.94 & 0.972 \\
Mixed & 1.86 & 1.79 & 1.87 & 1.92 & 1.85 & 0.132 & 0.121 \\
Ice & 0.121 & 0.116 & 0.122 & 0.126 & 0.121 & 0.132 \\
\hline Total ICS & 6.06 & 6.17 & 6.08 & 5.95 & 6.03 & 5.94 & 4.96 \\
Total BCS & 0.980 & 0.886 & 0.955 & 1.09 & 1.02 & 1.09 & 1.53 \\
Dry Deposition & 0.706 & 0.684 & 0.711 & 0.687 & 0.687 & 0.701 & 0.828 \\
Sedimentation & 0.024 & 0.023 & 0.024 & 0.024 & 0.024 & 0.024 & 0.436 \\
\hline
\end{tabular}

* Indicates that stratiform nucleation and impaction are included together in the result shown for stratiform nucleation.

Table 8. Similar to Table 6 except for particulate organic matter (POM) deposition $\left(\mathrm{Tg} \mathrm{yr}^{-1}\right)$.

\begin{tabular}{lccccccc}
\hline Organic Matter & CTL & F100 & F100-INT & DIAG1 & DIAG2 & DIAG-FULL & PROG-AP \\
\hline Stratiform clouds & & & & & & & \\
Warm nucleation & $14.9^{*}$ & $16.3^{*}$ & $15.3^{*}$ & 12.9 & 14.0 & 14.3 & $9.85^{*}$ \\
Mixed nucleation & $6.36^{*}$ & $6.20^{*}$ & $6.29^{*}$ & 3.94 & 4.66 & 4.83 & $3.14^{*}$ \\
Ice nucleation & $0.082^{*}$ & $0.110^{*}$ & $0.169^{*}$ & 0.376 & 0.277 & 0.318 & $0.476^{*}$ \\
Warm impaction & & & & 1.71 & 1.53 & 0.417 & \\
Mixed impaction & & & & 0.698 & 0.606 & 0.299 & \\
Ice impaction & & & & 0.066 & 0.045 & 0.004 & \\
\hline Convective clouds & & & & & & & \\
Warm & 10.1 & 9.86 & 9.99 & 10.3 & 10.0 & 10.1 & 9.51 \\
Mixed & 20.6 & 20.1 & 20.5 & 21.2 & 20.5 & 21.1 & 19.6 \\
Ice & 1.40 & 1.37 & 1.40 & 1.45 & 1.41 & 1.50 & 1.40 \\
\hline Total ICS & 53.4 & 53.9 & 53.7 & 52.6 & 53.0 & 52.9 & 44.2 \\
Total BCS & 6.75 & 6.32 & 6.48 & 7.53 & 7.12 & 7.30 & 11.3 \\
Dry Deposition & 5.92 & 5.88 & 5.91 & 5.82 & 5.83 & 5.80 & 7.05 \\
Sedimentation & 0.194 & 0.186 & 0.187 & 0.200 & 0.199 & 0.203 & 3.71 \\
\hline
\end{tabular}

* Indicates that stratiform nucleation and impaction are included together in the result shown for stratiform nucleation.

\subsubsection{Aerosol number deposition budgets}

Table 11 shows the annual and global mean number deposition attributed to the various physical processes. The diagnostic simulations show that aerosol number scavenged in stratiform clouds is primarily attributed to impaction scavenging processes, as opposed to nucleation processes. This is in agreement with the findings of the one-dimensional study of Jacobson (2003). For our diagostic scavenging simulations, impaction scavenging rates for aerosol number exceed the nucleation scavenging rates by more than one order of magnitude for mixed and ice phase clouds, which account for $99 \%$ of the total number removal in stratiform clouds. This result is expected since the majority of the aerosol number is in the nucleation mode that contains aerosols that are too small to be scavenged by cloud nucleation processes, and these aerosols are most abundant in the middle and upper troposphere at the altitudes of mixed and ice phase clouds. Differences to the parameterization of impaction scavenging between simulations DIAG2 and DIAG-FULL reduced the 
Table 9. Similar to Table 6 except for dust deposition $\left(\mathrm{Tg} \mathrm{yr}^{-1}\right)$.

\begin{tabular}{lccccccc}
\hline Dust & CTL & F100 & F100-INT & DIAG1 & DIAG2 & DIAG-FULL & PROG-AP \\
\hline Stratiform clouds & & & & & & & \\
Warm nucleation & $25.8^{*}$ & $31.5^{*}$ & $16.4^{*}$ & 15.4 & 16.8 & 15.2 & $10.2^{*}$ \\
Mixed nucleation & $29.5^{*}$ & $31.7^{*}$ & $17.7^{*}$ & 10.6 & 13.8 & 11.0 & $7.72^{*}$ \\
Ice nucleation & $0.308^{*}$ & $0.474^{*}$ & $1.04^{*}$ & 2.05 & 1.24 & 0.964 & $0.936^{*}$ \\
Warm impaction & & & & 0.030 & 0.027 & 12.1 & \\
Mixed impaction & & & & 0.191 & 0.172 & 13.6 & \\
Ice impaction & & & & 0.088 & 0.085 & 0.002 & \\
\hline Convective clouds & & & & & & & \\
Warm & 23.7 & 22.5 & 24.4 & 24.6 & 24.7 & 23.2 & 26.1 \\
Mixed & 34.4 & 32.9 & 36.0 & 37.1 & 36.9 & 35.1 & 39.3 \\
Ice & 2.31 & 2.18 & 2.37 & 2.41 & 2.45 & 2.45 & 2.69 \\
\hline Total ICS & 116. & 121. & 97.9 & 92.5 & 96.2 & 114. & 87.2 \\
Total BCS & 81.8 & 77.4 & 95.2 & 103. & 99.7 & 86.8 & 104.0 \\
Dry Deposition & 21.1 & 20.9 & 21.7 & 22.1 & 22.0 & 21.4 & 23.4 \\
Sedimentation & 122. & 120. & 124. & 126. & 126. & 123. & 129. \\
\hline
\end{tabular}

* Indicates that stratiform nucleation and impaction are included together in the result shown for stratiform nucleation.

Table 10. Similar to Table 6 except for sea salt $\left(\mathrm{Tg} \mathrm{yr}^{-1}\right)$.

\begin{tabular}{lccccccc}
\hline Sea Salt & CTL & F100 & F100-INT & DIAG1 & DIAG2 & DIAG-FULL & PROG-AP \\
\hline Stratiform clouds & & & & & & & \\
Warm nucleation & $740 .^{*}$ & $753 .^{*}$ & $753 .^{*}$ & 763. & 777. & 776. & $4^{*} .^{*}$ \\
Mixed nucleation & $624 .^{*}$ & $70 .^{*}$ & $704 .^{*}$ & 572. & 622. & 629. & $310 .^{*}$ \\
Ice nucleation & $0.41^{*}$ & $1.05^{*}$ & $1.04^{*}$ & 3.06 & 1.50 & 1.54 & $2.64^{*}$ \\
Warm impaction & & & & 0.044 & 0.019 & 2.64 & \\
Mixed impaction & & & & 0.096 & 0.056 & 3.53 & \\
Ice impaction & & & & 0.001 & 0.0004 & 0.022 & \\
\hline Convective clouds & & & & & & & \\
Warm & 285. & 282. & 282. & 284. & 280. & 282. & 304. \\
Mixed & 328. & 322. & 321. & 334. & 324. & 333. & 371. \\
Ice & 9.65 & 9.49 & 9.49 & 10.0 & 9.67 & 10.2 & 11.9 \\
\hline Total ICS & 1990. & 2070. & 2070. & 1970. & 2010. & 2040. & 1500. \\
Total BCS & 1240. & 1200. & 1200. & 1290. & 1260. & 1250. & 1530. \\
Dry Deposition & 933. & 913. & 913. & 915. & 912. & 910. & 1020. \\
Sedimentation & 1250. & 1230. & 1220. & 1220. & 1220. & 1210. & 1330. \\
\hline
\end{tabular}

* Indicates that stratiform nucleation and impaction are included together in the result shown for stratiform nucleation.

number scavenging for ice clouds by near to 7 times for the simulation DIAG-FULL. These results suggest that global modelers should give careful attention to the parameterization of impaction scavenging in predicting aerosol number scavenging in mixed and ice phase clouds. Considering all aerosol scavenging processes, in-cloud scavenging is the primary removal mechanism for aerosol number, exceeding dry deposition by up to one order of magnitude.

\section{Comparison with observations}

Figures 10 and 11 show the comparison of the modeled wet deposition of sulfate with the observations compiled by Dentener et al. (2006a), and grouped according to geographic region. We do not find any statistically significant difference between the CTL, DIAG-FULL, and PROG-AP simulations in comparison to these observations. For all these simulations, the modeled deposition is within a factor of two of the observations for at least $75 \%$ of the sites. However, we must 
Table 11. Global and annual mean aerosol number deposition $\left(10^{6} \mathrm{~m}^{-2} \mathrm{~s}^{-1}\right)$ summed over all aerosol modes.

\begin{tabular}{lcccccc}
\hline Number Dep & CTL & F100 & F100-INT & DIAG1 & DIAG2 & DIAG-FULL \\
\hline Stratiform clouds & & & & & & \\
Warm nucleation & $1.35^{*}$ & $21.3^{*}$ & $19.4^{*}$ & 0.61 & 0.64 & 0.56 \\
Mixed nucleation & $16.0^{*}$ & $259.5^{*}$ & $249.7^{*}$ & 0.49 & 0.53 & 0.44 \\
Ice nucleation & $22.7^{*}$ & $779.0^{*}$ & $777.8^{*}$ & 0.07 & 0.08 & 0.06 \\
Warm impaction & & & & 1.19 & 1.33 & 0.17 \\
Mixed impaction & & & & 6.11 & 8.03 & 6.32 \\
Ice impaction & & & & 36.7 & 46.3 & 6.68 \\
\hline Total ICS & 45.4 & 1080. & 1070 & 48.0 & 59.9 & 16.8 \\
Total BCS & 0.62 & 4.02 & 3.90 & 0.41 & 0.46 & 0.30 \\
Dry Deposition & 4.86 & 22.2 & 21.4 & 3.06 & 3.20 & 2.56 \\
Sedimentation & 0.002 & 0.002 & 0.002 & 0.002 & 0.002 & 0.002 \\
\hline
\end{tabular}

* Indicates that stratiform nucleation and impaction are included together in the result shown for stratiform nucleation.
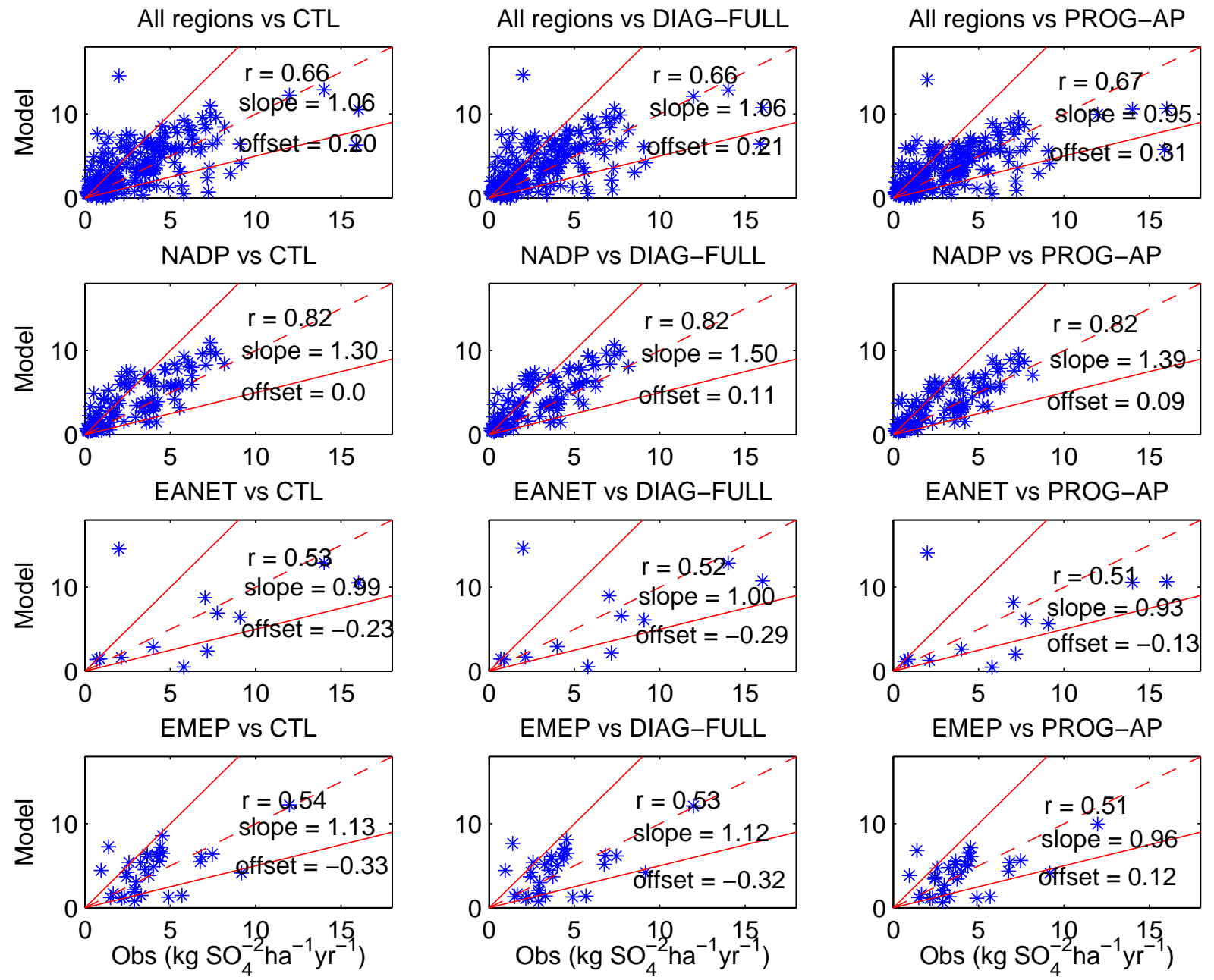

Fig. 10. The annual mean sulfate wet deposition $\left(\mathrm{kg} \mathrm{SO}_{4}^{-2} \mathrm{ha}^{-1} \mathrm{yr}^{-1}\right)$ grouped by regions from observations (Dentener et al., 2006a) as compared to the simulations CTL, DIAG-FULL and PROG-AP. The first row compiles data from all regions of this figure and Fig. 11. NADP is the National Atmospheric Deposition Program of the United States, EANET is the Acid Deposition Monitoring Network in East Asia, and EMEP is the European Monitoring and Evaluation Program. 

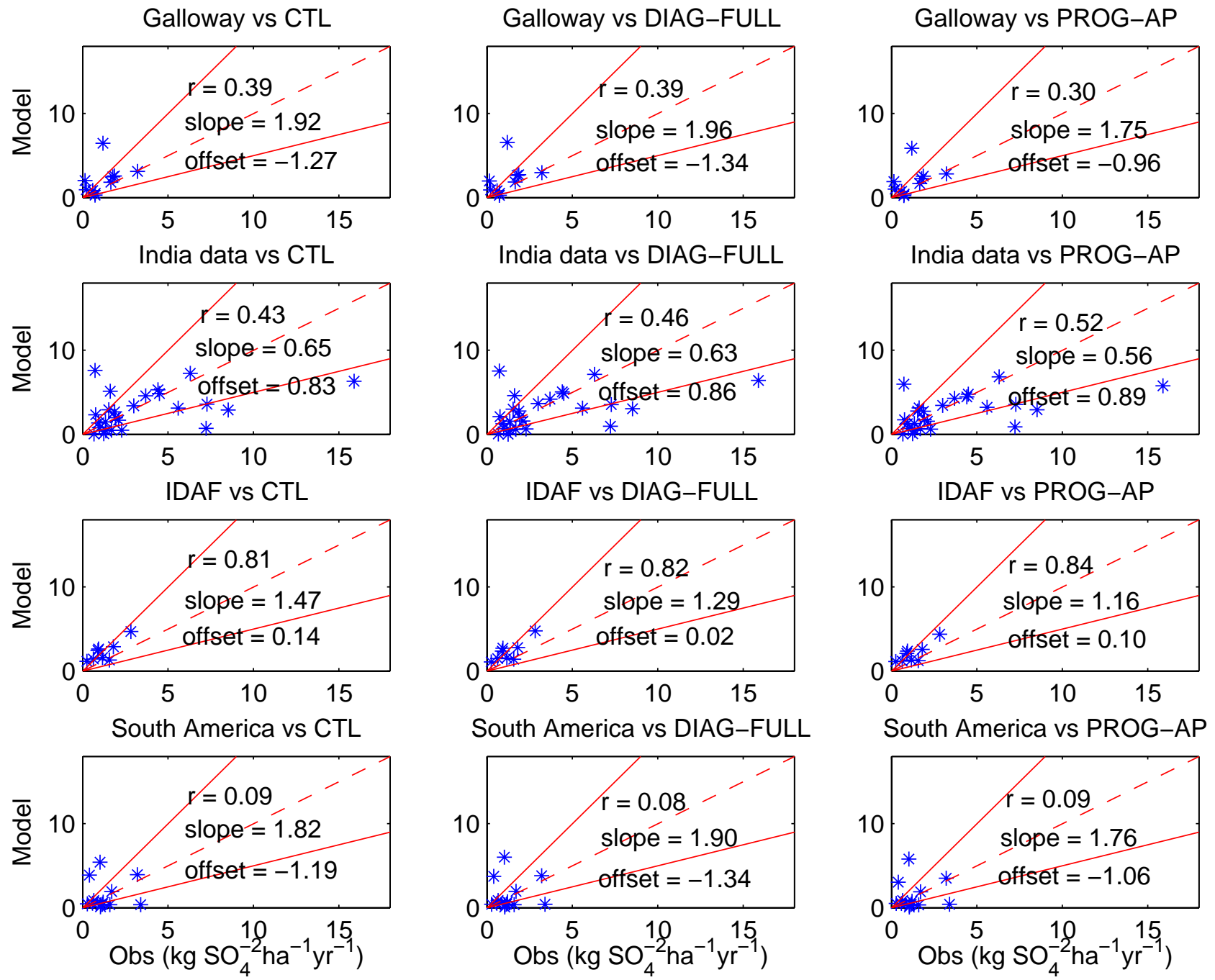

Fig. 11. The annual mean sulfate wet deposition $\left(\mathrm{kg} \mathrm{SO}_{4}^{-2} \mathrm{ha}^{-1} \mathrm{yr}^{-1}\right)$ grouped by regions from observations (Dentener et al., 2006a) as compared to the simulations CTL, DIAG-FULL and PROG-AP. Galloway refers to collection of sites from remote regions of primarily from the Australian and South American regions, and IDAF refers to a collection of data from Africa (Agac Debits Africa).

bear in mind the majority of sulfate mass, and thus the majority of the sulfate mass deposition is associated with scavenging in the near surface layers where cloud temperatures are frequently greater than $273 \mathrm{~K}$. Figure 3 shows that the scavenged fractions for the soluble accumulation and coarse aerosol modes (containing the majority of sulfate mass) are near to unity for warm phase clouds for both the CTL and DIAG-FULL simulations. Thus we would expect the simulations to compare equally well with observations for observations of sulfate wet deposition.

Figure 12 shows the geographic distribution of the aerosol optical depth (AOD) for the years 2001-2006, created from a combination of MODIS (Levy et al., 2007) and MISR (Diner et al., 2005; Martonchik et al., 2002) retrievals, as described in van Donkelaar et al. (submitted). The composite MODIS and MISR dataset is created from the ensemble of individual retrievals that exhibit little bias versus ground-based AERONET (Holben et al., 1998) AOD observations. More specifically, the accuracy of the MODIS and MISR AOD retrieval over land is evaluated relative to AERONET AOD on a monthly basis for nine land types defined using the MODIS BRDF/Albedo product at three different wavelengths $(470 \mathrm{~nm}, 660 \mathrm{~nm}$ and $2.1 \mu \mathrm{m})$. Daily MODIS and MISR AOD retrievals over land types that exhibit a mean monthly bias in excess of either 0.1 or $20 \%$ are rejected. The remaining retrievals over 2001-2006 are averaged. The composite dataset is driven by MISR observations over bright surfaces where MODIS is biased (Abdou et al., 2005), and over dark surfaces by MODIS (higher temporal sampling). MODIS AOD is used over the ocean due to high sampling frequency and accuracy (Remer et al., 2005). Annual mean AOD enhancements of $>0.5$ reflect a combination 

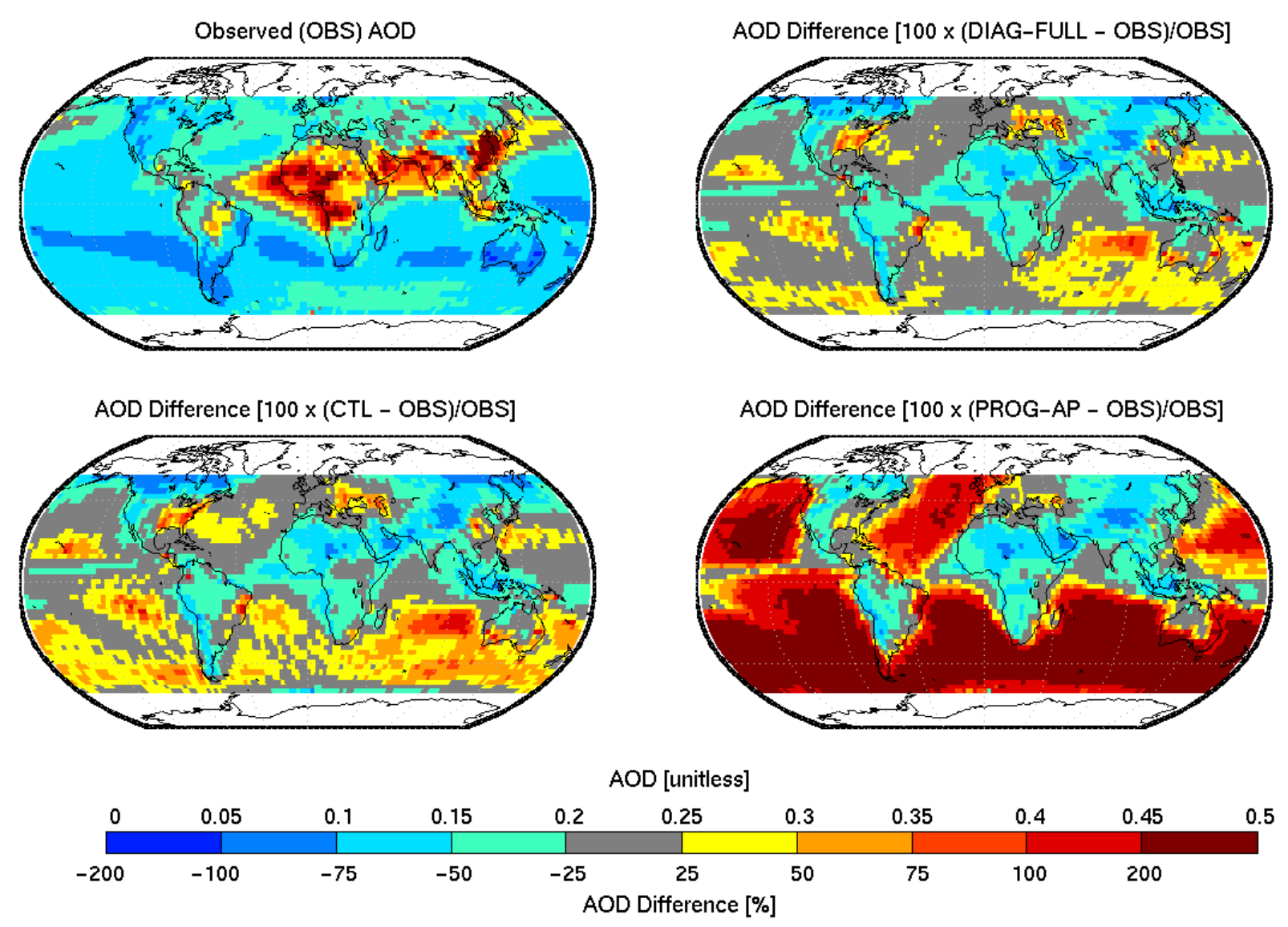

Fig. 12. The geographic distribution of aerosol optical depth (AOD) at $550 \mathrm{~nm}$ from the composite MODIS, MISR, AERONET dataset compiled by van Donkelaar et al. (submitted) representing the years 2001 to 2006, and the percent difference of the annual mean AOD for the simulations CTL, DIAG-FULL, and PROG-AP as compared to the observations.

of mineral dust over and downwind of Africa, as well as large anthropogenic signals over India and East Asia. Sea salt contributes to moderate AOD enhancements at southern high latitudes.

Figure 12 also shows the geographic distribution of the ratio of the aerosol optical depth (AOD) for the simulations CTL, DIAG-FULL, and PROG-AP compared to the observational dataset. Both the DIAG-FULL and CTL simulations perform similarly. However, the number of grid points within $25 \%$ of the observations is increased by near to $20 \%$ over the oceans for the DIAG-FULL simulation as compared to the CTL. The PROG-AP simulation has slightly lower AODs (10 to $20 \%$ ) over the land, which improves the agreement with observations over eastern North America and eastern Europe, but the AOD is considerably over-predicted over the oceans (up to a factor of two). Hoose et al. (2008a) have shown that the agreement over the oceans can be improved with changes to the water uptake on the aerosols, which will be implemented in future versions of the ECHAM5-HAM.

Hoose et al. (2008a) showed that a prognostic in-cloud scavenging scheme modified zonal mean aerosol size distributions in the marine boundary layer to produce better agreement with the observations of Heintzenberg et al. (2000), particularly for the accumulation mode. These observations are shown in Fig. 13. The observations of Heintzenberg et al. (2000) are a compilation of data from different mobility, and aerodynamic sizing techniques, operated at relative humidities of $<40 \%$, and a multi-modal lognormal distribution was fitted to the observations. The same methodology as described in Hoose et al. (2008a) was used for comparison with the simulations CTL, DIAG-FULL, and PROGAP. Figure 13 shows that the DIAG-FULL simulation, unlike the PROG-AP simulation, does not modify the marine accumulation mode size distribution significantly as compared to the CTL simulation. The Aitken mode number concentrations are under-estimated by up to five times over the southern oceans for all simulations in comparison to the observations. A considerable reduction in the under-estimation could be made with changes to the treatment of new particle formation in the marine boundary layer, which will be implemented in future ECHAM versions. For the DIAG-FULL simulation, the Aitken mode numbers are reduced by half in the Southern Hemisphere relative to the CTL simulation, which is a consequence of the more vigorous scavenging in 

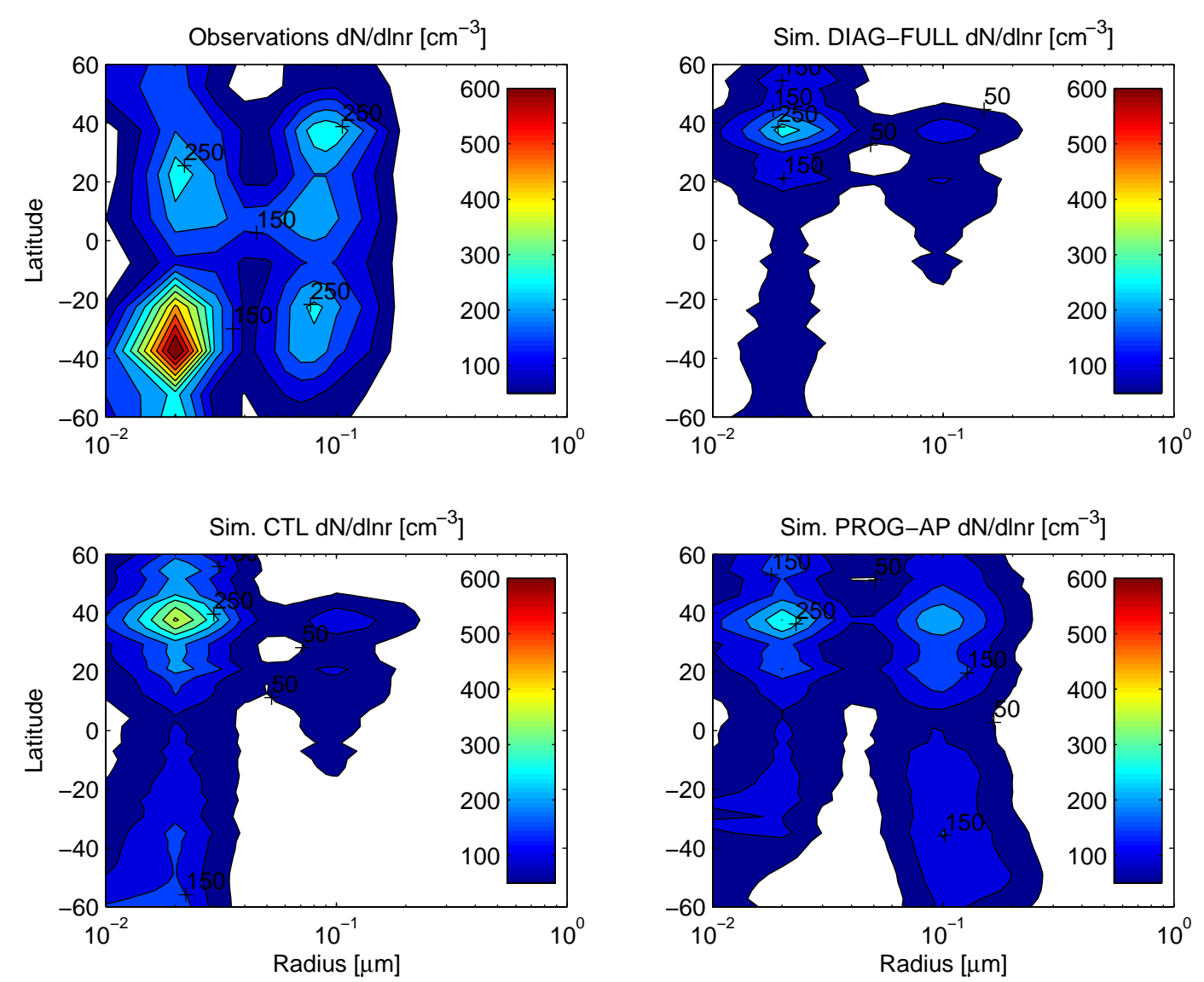

Fig. 13. Zonal mean aerosol size distributions in the marine boundary layer for the simulations CTL, DIAG-FULL, and PROG-AP as compared to the observations of Heintzenberg et al. (2000), and similar to Fig. 8 of Hoose et al. (2008a).

the marine boundary layer for the diagnostic scheme. Both Stier et al. (2005) and Hoose et al. (2008a) have shown that the size distributions for the ECHAM5-HAM model compare quite reasonably with observations. Accurate simulation of the aerosol size distributions in global models is also essential for the size-dependent in-cloud scavenging parameterizations to perform correctly.

Recently Koch et al. (2009) presented black carbon profiles observed from aircraft in comparison to various global models. Figures 14 and 15 compare this same aircraft data with our model simulations, CTL, DIAG-FULL, and PROGAP. Additionally we have included two sensitivity simulations that have the in-cloud impaction processes turned off for both the diagnostic and prognostic in-cloud scavenging schemes, DIAG-FULL-noimp and PROG-AP-noimp, respectively. Figure 14 shows profiles from the tropics and midlatitudes taken between the equator, and $50^{\circ} \mathrm{N}$ and between $120^{\circ} \mathrm{E}$ and $60^{\circ} \mathrm{E}$ and averaged for the same points as shown in Koch et al. $(2009,2010)$. Figure 15 presents profiles from the high latitudes taken between $50^{\circ} \mathrm{N}$ and $80^{\circ} \mathrm{N}$ and between $180^{\circ} \mathrm{E}$ and $60^{\circ} \mathrm{E}$ and averaged for the same points as shown in Koch et al. (2009, 2010). These figures show that the predicted black carbon profiles, particularly in the middle troposphere differ from the observations, and between each other, by up to two orders of magnitude depending on the treatment of in-cloud scavenging. Changes of this magnitude could influence predictions of both the direct and indirect effects of aerosols, particularly related to black carbon in the middle and upper troposphere. These effects should be investigated in future studies. For the high latitude profiles shown in Fig. 15, where mixed phase and ice clouds are more prevalent, the CTL simulation underestimates the concentrations by up to two orders of magnitude, and both DIAG-FULL and PROG-AP improve the agreement to within one order of magnitude. For the simulation PROG-AP, black carbon concentrations are lower by up to a factor of five, and two in the middle and upper troposphere, respectively, as compared to the simulation PROGAP-noimp. Thus, the parameterization of impaction scavenging is particularly relevant for black carbon in mixed and ice phase clouds.

For black carbon, the parameterization of impaction scavenging is of importance since this aerosol has considerable mass in the insoluble Aitken mode, which is scavenged only 

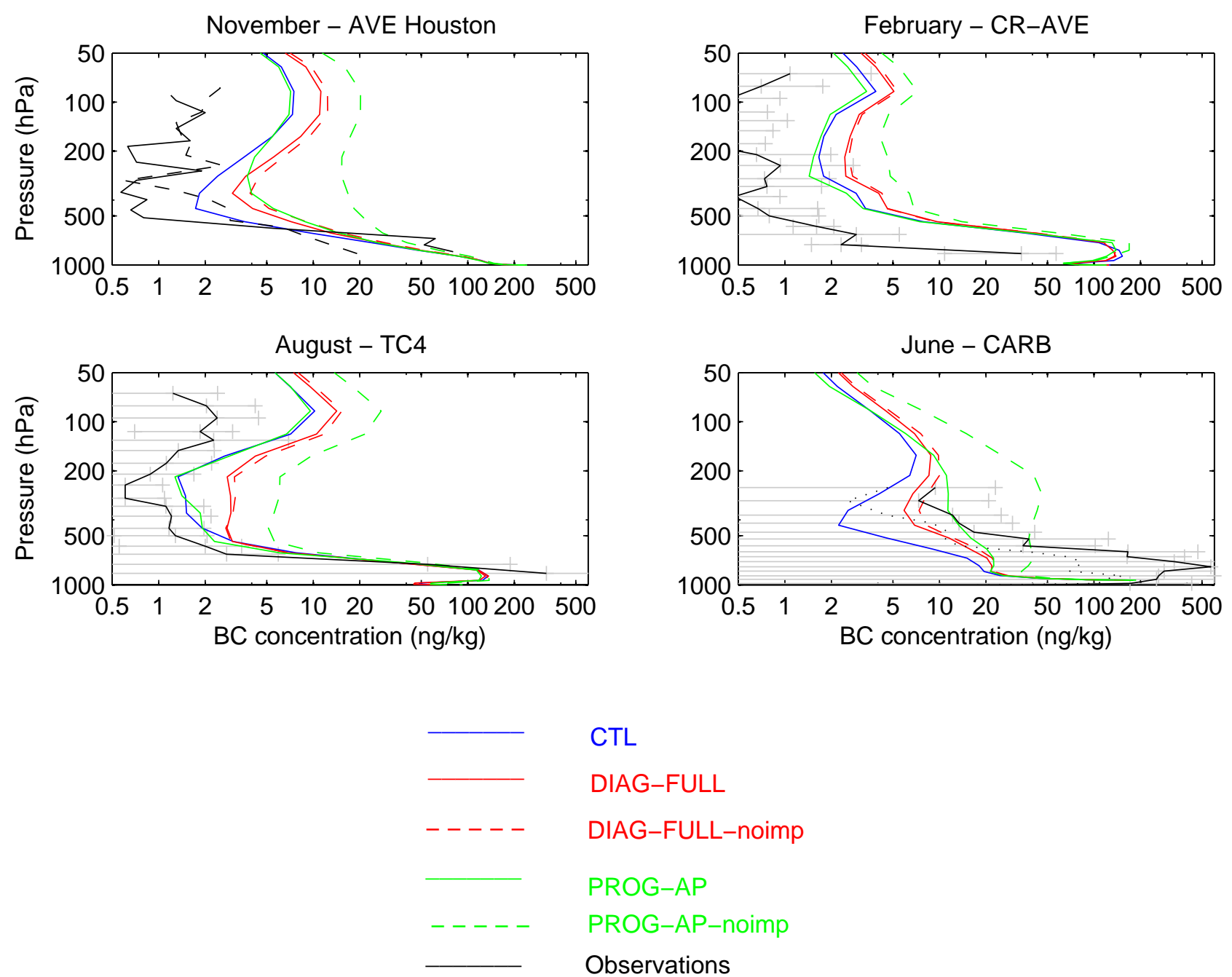

Fig. 14. Black carbon concentrations $\left(\mathrm{ng} \mathrm{kg}^{-1}\right)$ from the tropical and mid-latitude aircraft campaigns over the Americas between the equator and $50^{\circ} \mathrm{N}$, and $120^{\circ} \mathrm{E}$ and $60^{\circ} \mathrm{E}$, for the same locations as described in Fig. 9 of Koch et al. (2009), and for the simulations CTL, DIAGFULL, and PROG-AP, and with no impaction scavenging for DIAG-FULL-noimp and PROG-AP-noimp. AVE-Houston: NASA Houston Aura Validation Experiment, CR-AVE: NASA Costa Rica Aura Validation Experiment, TC4: NASA Tropical Composition, Cloud, and Climate Coupling, CARB: NASA initiative in collaboration with California Air Resources Board.

by impaction processes. This parameterization also relies on the correct representation of black carbon aging to determine the correct distribution of mass between the soluble/internally mixed and insoluble modes, making prediction of black carbon concentrations challenging. For seven of the ten of the profiles presented, the black carbon profile is closer to the observations for the DIAG-FULL and PROG-AP simulations as compared to the CTL simulation (changes up to one order of magnitude), suggesting that the mixed phase prescribed scavenging fractions of the CTL simulation might be too large. For the three profiles of Fig. 14 that show closer agreement with observations for the prescribed coefficient scheme of the CTL simulation, the PROG-AP simulation is a better match to the observations than for the DIAG-FULL simulation.

\subsection{Simulation of ${ }^{210} \mathrm{~Pb}$ and ${ }^{7} \mathrm{Be}$}

${ }^{7} \mathrm{Be}$ and ${ }^{210} \mathrm{~Pb}$ have been simulated in global models, and used as passive tracers for the validation of deposition parameterizations (e.g., Brost et al., 1991; Liu et al., 2001; Feichter et al., 1991; Koch et al., 1996, 2006). Recently, simulation of ${ }^{7} \mathrm{Be}$ and ${ }^{210} \mathrm{~Pb}$ have been introduced into the ECHAM5-HAM (Heikkilä et al., 2008, 2009). The methodology is described in detail in Feichter et al. (1991); Heikkilä (2007); Heikkilä et al. (2008). The production rates for ${ }^{7} \mathrm{Be}$ were taken from Masarik and Beer (1999). The ${ }^{210} \mathrm{~Pb} / \mathrm{radon}$ source is from soils and was taken to be 1 atoms cm$~^{-2} \mathrm{~s}^{-1}$, following Feichter et al. (1991); Liu et al. (2001); Koch et al. (2006). ${ }^{7} \mathrm{Be}$ and ${ }^{210} \mathrm{~Pb}$ are not explicitly distributed into the aerosol modes of the ECHAM5-HAM. However, the 

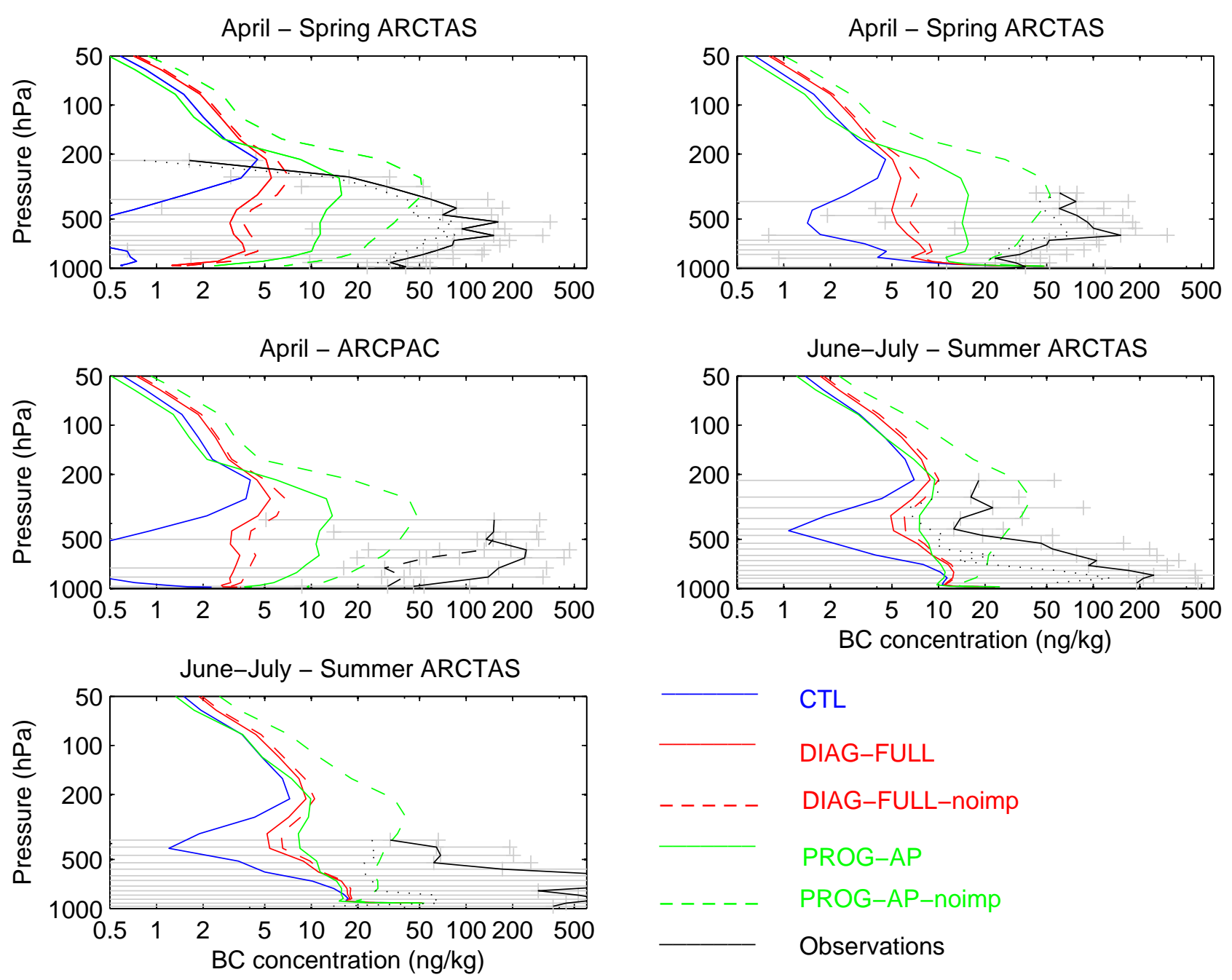

\section{Observations}

Fig. 15. Black carbon concentrations $\left(\mathrm{ng} \mathrm{kg}^{-1}\right.$ ) from the high latitude aircraft campaigns over the Americas between $50^{\circ} \mathrm{N}$ and $80^{\circ} \mathrm{N}$, and $180^{\circ} \mathrm{E}$ and $60^{\circ} \mathrm{E}$, for the same locations as described in detail in Fig. 10 of Koch et al. (2009), and for the simulations CTL, DIAG-FULL, and PROG-AP, and with no impaction scavenging for DIAG-FULL-noimp and PROG-AP-noimp. ARCTAS: NASA Arctic Research of the Composition of the Troposphere from Aircraft and Satellites, ARCPAC: NOAA Aerosol Radiation and Cloud Processes affecting Arctic Climate.

scavenging fractions for ${ }^{7} \mathrm{Be}$ are found by taking the ratio of the total sulfate mass scavenged to the total aerosol mass, whereas for ${ }^{210} \mathrm{~Pb}$ the scavenging fractions are determined by the ratio of the total aerosol mass scavenged to the total aerosol mass. The rationale is that near the surface where ${ }^{210} \mathrm{~Pb}$ is formed, particles are composed of many chemical compounds, whereas for the ${ }^{7} \mathrm{Be}$ source in the stratosphere, and upper troposphere, sulfate is the dominant chemical compound. These tracers have been coupled with the CTL and DIAG-FULL simulations.

Figure 16 compares the surface layer concentrations and wet deposition of these tracers for the simulations CTL and DIAG-FULL with observations described in Heikkilä (2007); Heikkilä et al. (2008). The comparison with observed surface layer concentrations and wet deposition is more robust for ${ }^{210} \mathrm{~Pb}$ than for ${ }^{7} \mathrm{Be}$ since ${ }^{210} \mathrm{~Pb}$ originates from surface sources and rarely reaches the stratosphere. ${ }^{210} \mathrm{~Pb}$ has a relatively long half-life with respect to radioactive decay processes (22.4 years), but a relatively short atmospheric residence time (3-5 days) due to wet deposition processes. Conversely, the ${ }^{7} \mathrm{Be}$ source is in the upper atmosphere and ${ }^{7} \mathrm{Be}$ has a shorter half-life (few months). The longer transport path from source to the cloud levels or surface, coupled with the shorter half-life, increases the uncertainty associated with comparisons between the modeled and observed deposition and surface layer concentrations for ${ }^{7}$ Be. Nevertheless, Fig. 16 shows that both tracers are simulated reasonably in comparison with observations of deposition and surface layer concentrations. We not find any statistically significant improvement for the DIAG-FULL 

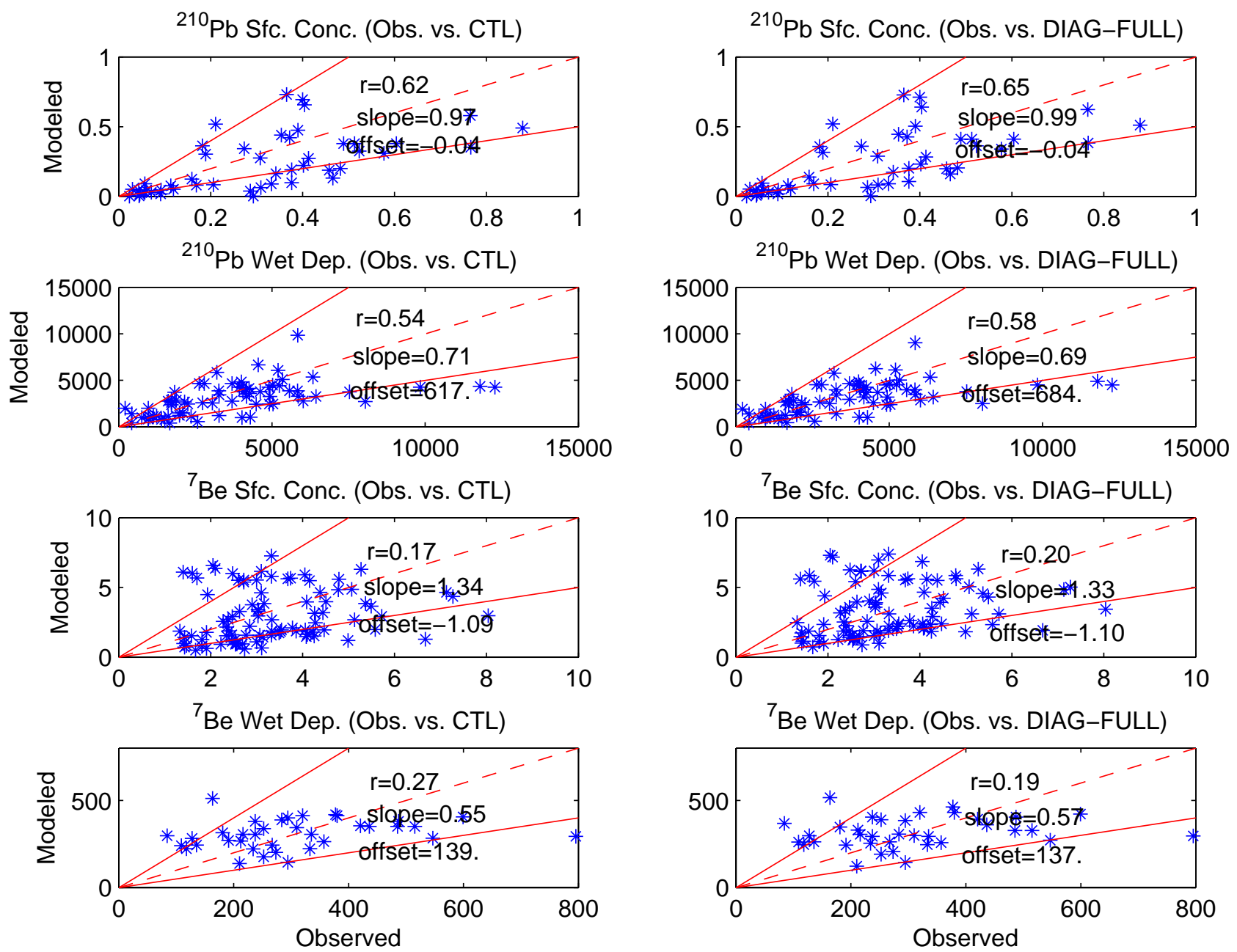

Fig. 16. Annual mean surface layer concentrations $\left(\mathrm{mBqm}^{-3}\right.$ at STP) and wet deposition (atoms $\left.\mathrm{m}^{-2} \mathrm{~s}^{-1}\right)$ of ${ }^{210} \mathrm{~Pb}$ and ${ }^{7} \mathrm{Be}$ from observations described in Heikkilä (2007); Heikkilä et al. (2008) compared to the simulations CTL and DIAG-FULL.

scheme in comparison to the CTL. This is not unexpected since as discussed in reference to Figs. 10 and 11, the surface layer concentrations and mass deposition are strongly controlled by warm cloud scavenging processes, which do not change as significantly between the various scavenging parameterizations as does the scavenging in mixed and ice phase clouds. In making these comparisons, we must also keep in mind that the deposition observations presented do not have a global coverage as extensive as for the surface layer concentration observations. Additionally, there are uncertainties in the comparison with observations related to discrepancies between the modeled and observed meteorological conditions at the measurement sites, and the grid size of the model which does not resolve local conditions at the measurement sites. The best correlation coefficients, slope and offset parameters are for the case of ${ }^{210} \mathrm{~Pb}$ surface layer concentrations. However, for both deposition and surface layer concentration, the DIAG-FULL and CTL simulations are within a factor of two of the observations at more than $75 \%$ of the sites.

Since aerosol concentrations in the middle and upper troposphere are most sensitive to differences in the parameterization of in-cloud scavenging, we present additional comparisons with observed vertical profiles of ${ }^{210} \mathrm{~Pb},{ }^{7} \mathrm{Be}$ and sulfate in Figs. 17 and 18. Figure 17 repeats the comparisons of Liu et al. (2001) for a variety of sites in the Pacific. We have made this comparison for the same months and regions as defined in Liu et al. (2001). Particularly for the middle latitude sites (WPML and CPML), ${ }^{210} \mathrm{~Pb}$ concentrations are underestimated by the model in the middle troposphere. The new diagnostic scavenging for the simulation DIAG-FULL increases the concentrations by up to $30 \%$, which improves the agreement. However, since these are sites that are also influenced by convective scavenging, revisions to the convective 
CPML
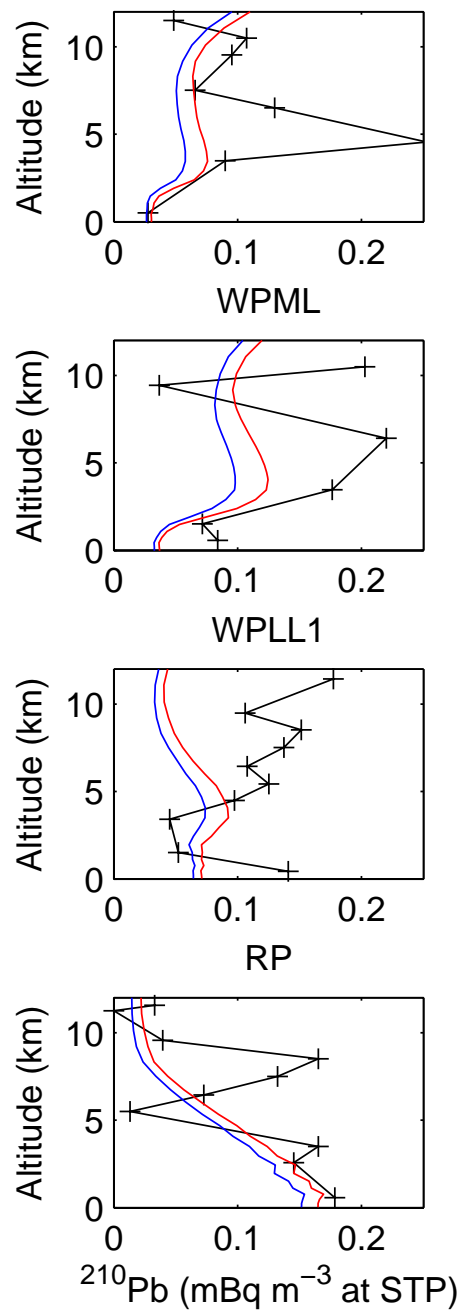

CPML
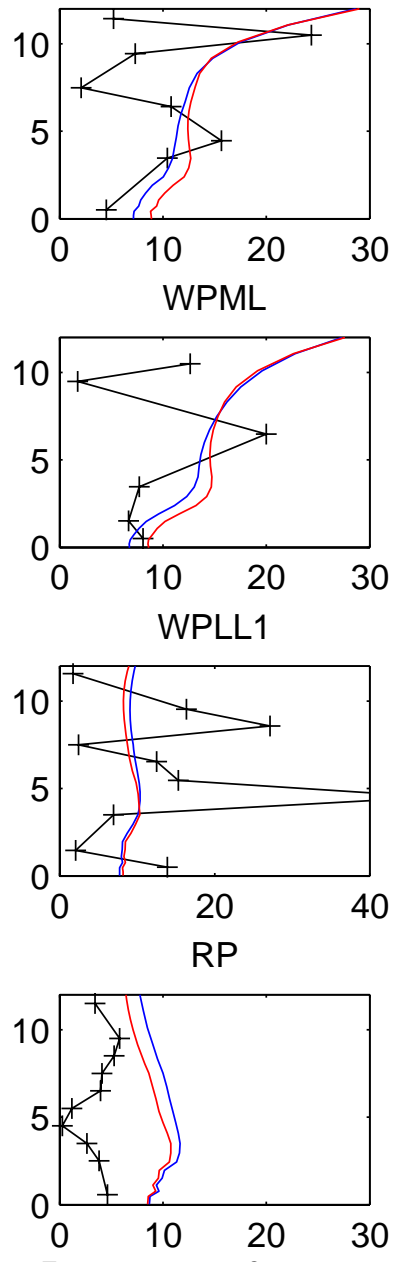

${ }^{7} \mathrm{Be}\left(\mathrm{mBq} \mathrm{m} \mathrm{m}^{-3}\right.$ at STP)
CPLL
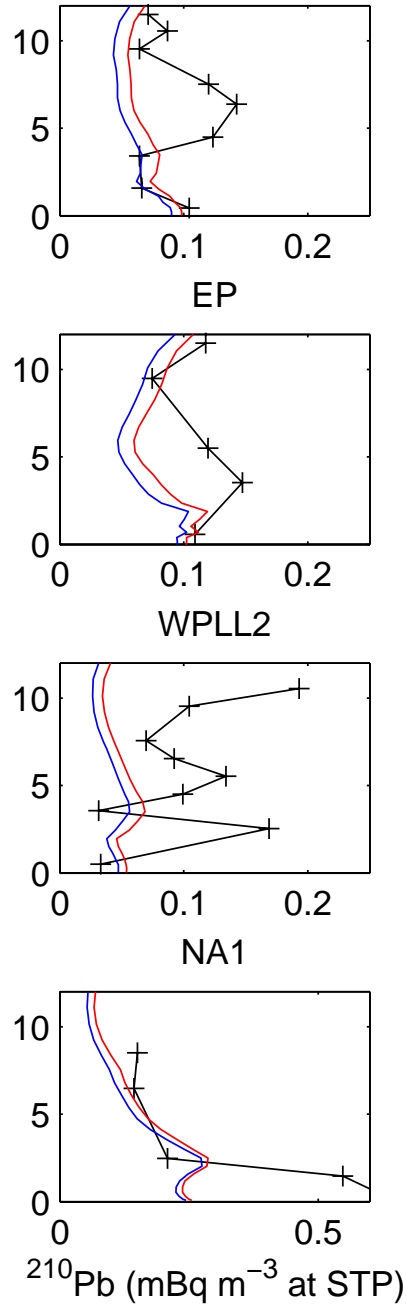

CPLL
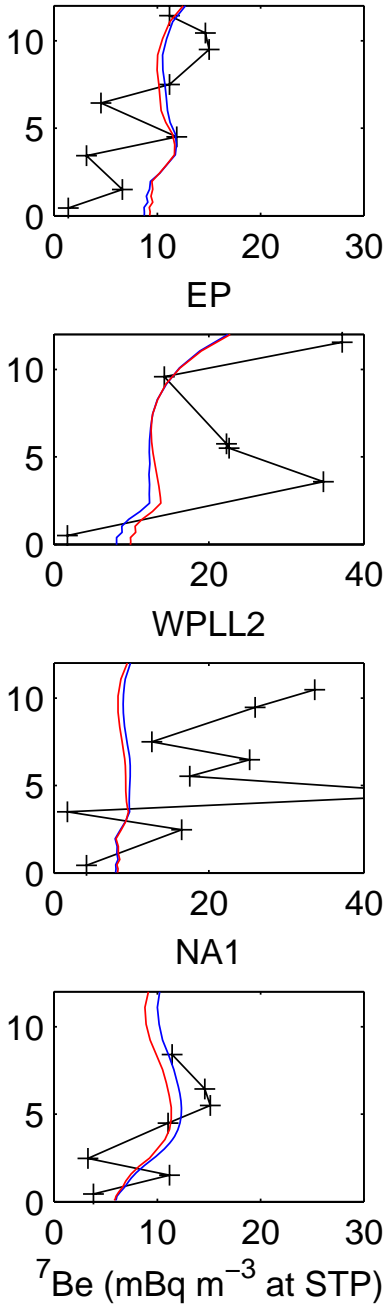

Fig. 17. Vertical profiles of ${ }^{210} \mathrm{~Pb}$ and ${ }^{7} \mathrm{Be}$ concentration $\left(\mathrm{mBq} \mathrm{m}{ }^{-3}\right.$ at STP) observed by PEM-Tropics A and PEM-West B aircraft campaigns and for the same regions of the Pacific described in detail in Liu et al. (2001) and compared with simulations CTL and DIAGFULL. PEM-Tropics A: NASA Pacific Exploratory Mission includes CPML: Central Pacific mid-latitude, WPML: West Pacific mid-latitude, CPLL: Central Pacific low latitude, WPLL: West Pacific low latitude, EP: East Pacific. PEM-West B: NASA Pacific Exploratory Mission in the western Pacific includes RP: remote Pacific, NA1: near Asia. Red: DIAG-FULL simulation, Blue: CTL simulation, Black: Observations.

scavenging could improve the agreement further. Figure 18 shows that the modeled ${ }^{210} \mathrm{~Pb}$ concentrations for the middle troposphere of the more northerly latitudes are most sensitive to changes to the stratiform in-cloud scavenging. There is improved agreement between the modeled annual mean, and the mean of the Kownacka (2002) multi-year (19871998) dataset from Poland between the altitudes of 4 and $8 \mathrm{~km}$, as shown by the right hand column of Fig. 18. The two left hand columns of Fig. 18 show aircraft data from the Environmental Measurement Laboratory described in detail in Heikkilä (2007). The modeled zonal and annual mean ${ }^{7} \mathrm{Be}$ and ${ }^{210} \mathrm{~Pb}$ concentrations above $15 \mathrm{~km}$ (shown in the two left columns) are not sensitive to the differences between our incloud scavenging schemes, but are shown to match well with the observations. ${ }^{7} \mathrm{Be}$ is underestimated near the tropopause as was also found by Liu et al. (2001); Koch et al. (2006); Heikkilä et al. (2008). Figure 18 also shows a comparison with sulfate data from the TRACEP campaign of 2001. Sulfate concentrations are increased by near to $50 \%$ for the PROG-AP, as compared to CTL simulation, for altitudes near $5 \mathrm{~km}$. This is a smaller change than was found for black carbon profiles. While this change does not appear to be in better agreement with the observations, this does not necessarily indicate a problem with the scavenging parameterizations since $\mathrm{SO}_{2}$ concentrations (not shown) were also similarly high in our model for this same comparison. We must be careful not to over interpret results from comparison to aircraft campaigns since the spatial and temporal averaging 

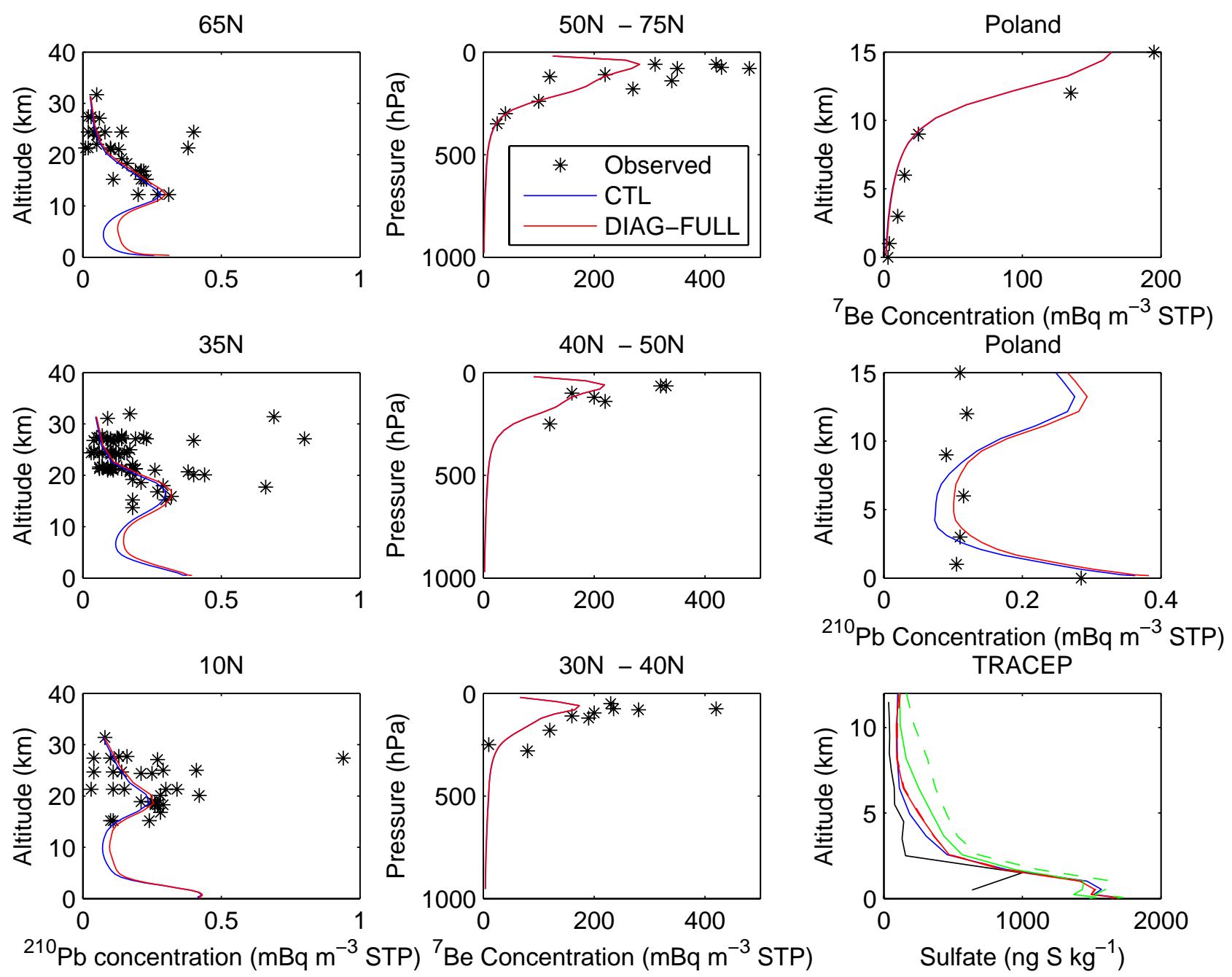

Fig. 18. Vertical profiles of ${ }^{210} \mathrm{~Pb}$ and ${ }^{7} \mathrm{Be}$ concentration $\left(\mathrm{mBq} \mathrm{m}^{-3}\right.$ at $\left.\mathrm{STP}\right)$ observed by aircraft campaigns from the Environment Measurements Laboratory (EML) High Altitude Sampling Program (HASP) are shown in the two left columns, and the mean of the multi-year (1987-1998) dataset of Kownacka (2002) is shown in the right column. Modeled concentrations are zonal means for the two left columns, and for the grid box over Poland for the panels labeled Poland. The bottom right panel shows sulfate (ng kg ${ }^{-1}$ ) observations from the TRACEP campaign (http://www-gte.larc.nasa.gov/) for March 2001 and for the region between 120 to $140^{\circ}$ E, and 20 to $35^{\circ} \mathrm{N}$. For TRACEP panel only: Green: PROG-AP, Dashed: DIAG-FULL-noimp and PROG-AP-noimp. Note: if DIAG-FULL overlaps CTL, only red is shown; for TRACEP, DIAG-FULL-noimp nearly overlaps DIAG-FULL.

differs between the model and observations. However, these comparisons do illustrate that the new diagnostic scavenging parameterization for stratiform clouds works quite reasonably, and particularly at mid- and high latitudes does produce results that agree equally or better with many of the observed middle troposphere profiles.

\section{Summary and conclusions}

A cloud nucleation scavenging scheme that diagnoses scavenging ratios for aerosol mass and number distributions based on cloud droplet and ice crystal number concentrations has been coupled with a physically detailed size-dependent in-cloud impaction scavenging parameterization, and implemented for stratiform clouds in the ECHAM5-HAM model. In the global and annual mean, the aerosol mass scavenged in stratiform clouds was found to be primarily (>90\%) scavenged by nucleation processes, except for dust $(50 \%)$. The aerosol number scavenged was found to be primarily $(>90 \%)$ attributed to impaction processes. Scavenging in clouds with temperatures below $273 \mathrm{~K}$ accounted for more than $99 \%$ of this number scavenging. The majority of the aerosol number resides in the nucleation mode size range, which is too small to be scavenged by cloud nucleation processes, and is most abundant in the colder regions of the middle and upper troposphere. 
Predicted aerosol concentrations, burdens and deposition have been compared between simulations that implemented the new diagnostic scheme, the prescribed scavenging fractions of the standard ECHAM5-HAM, and the prognostic aerosol cloud processing approach of Hoose et al. (2008a,b). The prescribed fractions approach was the least computationally expensive, but was not as physically detailed as the diagnostic and prognostic schemes, and was not able to represent the variability of scavenged fractions, particularly for submicron size particles and for mixed and ice phase clouds. As a result, the diagnostic and prognostic schemes are recommended as preferable to the prescribed fraction scheme. The global and annual mass burdens increased by up to $30 \%$ and $15 \%$, for sea salt and dust, respectively, and the accumulation mode number burden increased by near to $50 \%$, for the prognostic scheme relative to the diagnostic scheme. Aerosol mass concentations in the middle troposphere were increased, by up to one order of magnitude for black carbon, for the diagnostic and progostic schemes compared to the prescribed scavenging fraction approach. Thus, uncertainties in the parameterization of in-cloud scavenging can lead to significant differences in predicted middle troposphere aerosol vertical profiles, particularly for mixed and ice phase clouds. Additionally, we recommend that the next generation of aerosol microphysical models should give careful attention to the representation of impaction processes, particularly in mixed and ice phase clouds, and for dust at all cloud temperatures. Different impaction parameterizations changed the global and annual mean stratiform dust mass removal attributed to impaction by more than two orders of magnitude, which illustrates the considerable uncertainty related to in-cloud impaction scavenging. For the prognostic scheme, exclusion of parameterized impaction increased the the global, annual accumulation mode number burden by near to $60 \%$.

In comparison with observations, the prescribed scavenging ratio scheme of the standard ECHAM5-HAM underestimated black carbon profiles observed from aircraft by up to two orders of magnitude. The revised diagnostic and prognostic scavenging schemes improved the agreement to within one order of magnitude. This strengthens our recommendation of the diagnostic and prognostic schemes as preferable to the prescribed scavenging ratio approach. In comparison with observed profiles of ${ }^{210} \mathrm{~Pb}$, the new diagnostic scheme increased ${ }^{210} \mathrm{~Pb}$ concentration by up to $30 \%$ in the middle troposphere, which improved the agreement for several mid- and high latitude sites. Comparing with observations of sulfate and ${ }^{210} \mathrm{~Pb}$ wet deposition, the new diagnostic scheme was found to perform similarly to the prescribed scavenging coefficient approach of Stier et al. (2005). This was not unexpected since the majority of aerosol mass resides in the lower troposphere where warm clouds are most frequent. Our results show that the in-cloud scavenging parameterizations are quite similar for warm phase clouds, and for the scavenging of the accumulation and coarse aerosol modes that contain the majority of the mass. The diagnostic scheme increased the number of grid points within $25 \%$ of the observed aerosol optical depth over the oceans by $20 \%$, as compared to the CTL simulation that also over-predicted aerosol optical depth over the oceans. For these comparisons, we have used a new aerosol optical depth climatology (20012006) produced from a combination of MODIS, MISR, and AERONET observations, and have used this to evaluate our simulations.

The prognostic aerosol cloud processing scheme used for this study does require 10 additional tracers, and thus diagnostic scavenging schemes can be desirable in global models due their relative simplicity. However, prognostic aerosol processing schemes, such that of Hoose et al. (2008a,b) are beneficial, and future work should be directed towards extending this prognostic approach to convective clouds, particularly since convective scavenging does account for near to $50 \%$ of global wet scavenging. We also recommend that the more physically detailed impaction scavenging parameterization of the diagnostic scheme should be coupled with the prognostic cloud processing scheme. Since the global annual mean sulfate mass burdens increased by $10 \%$ for the diagnostic scheme when the mass and number nucleation scavenging ratios were equated, as opposed to determined separately, we recommend that the prognostic scheme should be developed to implement separate nucleation scavenging ratios for aerosol number and mass.

Finally, in a more general sense future work should be directed towards examining the influence of these uncertainties in the parameterization of in-cloud scavenging on the aerosol direct and indirect effects upon the climate system, particularly given the sensitivity of the predicted middle and upper tropospheric aerosol concentrations to the in-cloud scavenging parameterization. Additionally, efforts should be ongoing to improve understanding of the impaction scavenging process, particularly in clouds with temperatures below $273 \mathrm{~K}$. This is relevant since aerosol number scavenging in stratiform clouds was found to be primarily attributed to the impaction process in mixed and ice phase clouds, and dust mass scavenging in stratiform clouds was found to be attributed equally to nucleation and impaction scavenging processes.

Acknowledgements. The authors are grateful to the National Science and Engineering Research Council of Canada and Killam Trusts Foundation of Canada for financial support. We thank D. Koch, and the following groups associated with providing aircraft data: NOAA at UC Boulder (David Fahey), University of Tokyo (Y. Kondo), and University of Hawaii (T. Clarke). Thanks also to CSCS for computing time.

Edited by: J. H. Seinfeld 


\section{References}

Abdou, W. A., Diner, D. J., Matonchik, J. V., Bruegge, C. J., Kahn, R. A., Gaitley, B. J., Crean, K. A., Remer, L. A., and Holben, B.: Comparison of coincident Multiangle Imaging Spectroradiometer aerosol optical depths over land and ocean scenes containing Aerosol Robotic Network sites, J. Geophys. Res., 110, D10S07, doi:10.1029/2004JD004693, 2005.

Adams, P. J. and Seinfeld, J. H.: Predicting global aerosol size distributions in general circulation models, J. Geophys. Res., 107, 4370, doi:10.1029/2001JD001010, 2002.

Barth, M., Rasch, P. J., Kiehl, J. T., Benkovitz, C. M., and Schwartz, S. E.: Sulfur chemistry in the NCAR CCM: Description, evaluation, features and sensitivity to aqueous chemistry, J. Geophys. Res., 105, 1387-1415, 2000.

Baumgardner, D., Subramanian, R., Twohy, C., Stith, J., and Kok, G.: Scavenging of black carbon by ice crystals over the northern Pacific, Geophys. Res Lett., 35, L22815, doi:10.1029/2008GL035764, 2008.

Brost, R., Feichter, J., and Heimann, M.: Three-dimensional simulation of ${ }^{7} \mathrm{Be}$ in a Global Climate Model, J. Geophys. Res., 96(D12), 22423-22445, 1991.

Cagnazzo, C., Manzini, E., Giorgetta, M. A., Forster, P. M. De F., and Morcrette, J. J.: Impact of an improved shortwave radiation scheme in the MAECHAM5 General Circulation Model, Atmos. Chem. Phys., 7, 2503-2515, 2007, http://www.atmos-chem-phys.net/7/2503/2007/.

Charlson, R. J., Schwartz, S. E., Hales, J. M., Cess, R. D., Coakley, J. A., Hansen, J. E., and Hofmann, D. J.: Climate forcing by anthropogenic aerosols, J. Geophys. Res., 255, 423-430, 1992.

Chin, M., Rood, R. B., Lin, S.-J., Muller, J.-F., and Thompson, A. M.: Atmospheric sulfur cycle in the global model GOCART: Model description and global properties, J. Geophys. Res., 105, 24661-24687, 2000.

Croft, B., Lohmann, U., Martin, R. V., Stier, P., Wurzler, S., Feichter, J., Posselt, R., and Ferrachat, S.: Aerosol size-dependent below-cloud scavenging by rain and snow in the ECHAM5HAM, Atmos. Chem. Phys., 9, 4653-4675, 2009, http://www.atmos-chem-phys.net/9/4653/2009/.

Dentener, F., Drevet, J., Lamarque, J. F., Bey, I., Eickhout, B., Fiore, A. M., Haiglustaine, D., Horowitz, L. W., Krol, M., Lawrence, U. C., Galy-Lacaux, C., Rast, S., Shindell, D., Stevenson, D., Noije, T. V., Atherton, C., Bell, N., Bergman, D., Butler, T., Cofala, J., Colins, B., Doherty, R., Ellingsen, K., Galloway, J., Gauss, M., Montanaro, V., Müller, J. F., Pitari, G., Rodriguez, J., Sanderson, M., Solomon, F., Strahan, S., Schultz, M., Sudo, K., Szopa, S., and Wild, O.: Nitrogen and sulfur deposition on regional and global scales: A multimodel evaluation, Global Biogeochem. Cy., 20, GB4003, doi:10.1029/2005GB002672, 2006a.

Dentener, F., Kinne, S., Bond, T., Boucher, O., Cofala, J., Generoso, S., Ginoux, P., Gong, S., Hoelzemann, J. J., Ito, A., Marelli, L., Penner, J. E., Putaud, J.-P., Textor, C., Schulz, M., van der Werf, G. R., and Wilson, J.: Emissions of primary aerosol and precursor gases in the years 2000 and 1750 prescribed data-sets for AeroCom, Atmos. Chem. Phys., 6, 4321-4344, 2006b, http://www.atmos-chem-phys.net/6/4321/2006/.
Diner, D. D., Braswell, B. H., Davies, R., Gobron, N., Hu, J., Jin, Y., Kahn, R. A., Knyazikhin, Y., Loeb, N., Muller, J.-P., Nolin, A. W., Pinty, B., Schaaf, C. B., Seiz, G., and Stroeve, J.: The value of multiangle measurements for retrieving structurally and radiatively consistent properties of cloud, aerosols and surfaces, Remote Sens. Environ., 97, 495-518, 2005.

Feichter, J., Brost, R. A., and Heimann, M.: Three-dimensional modeling of the concentration and deposition of ${ }^{210} \mathrm{~Pb}$ aerosols, J. Geophys. Res., 96(D12), 22447-22460, 1991.

Ghan, S. J. and Easter, R. C.: Impact of cloud-borne aerosol representation on aerosol direct and indirect effects, Atmos. Chem. Phys., 6, 4163-4174, 2006, http://www.atmos-chem-phys.net/6/4163/2006/.

Ghan, S. J., Chuang, C. C., and Penner, J. E.: A parameterization of cloud droplet nucleation part I: single aerosol type, Atmos. Res., 30, 198-221, 1993.

Gong, S. L., Barrie, L. A., Blanchet, J.-P., vonSalzen, K., Lohmann, U., Lesins, G., Spacek, L., Zhang, L. M., Girard, E., Lin, H., Leaitch, R., Leighton, H., Chylek, P., and Huang, P.: Canadian Aerosol Module: A size-segregated simulation of atmospheric aerosol processes for climate and air quality models: 1. Module developments, J. Geophys. Res., 108, 4007, doi:10.1029/2001JD002002, 2003.

Heikkilä, U.: Modeling of the atmospheric transport of the cosmogenic radionuclides ${ }^{10} \mathrm{Be}$ and ${ }^{7} \mathrm{Be}$ using the ECHAM5-HAM General Circulation Model, available from http://e-collection. ethbib.ethz.ch., last access: 11 February 2010, PhD thesis, Dissertation ETH No. 17516, 2007.

Heikkilä, U., Beer, J., and Feichter, J.: Modeling cosmogenic radionuclides ${ }^{10} \mathrm{Be}$ and ${ }^{7} \mathrm{Be}$ during the Maunder Minimum using the ECHAM5-HAM General Circulation Model, Atmos. Chem. Phys., 8, 2797-2809, 2008, http://www.atmos-chem-phys.net/8/2797/2008/.

Heikkilä, U., Beer, J., and Feichter, J.: Meridional transport and deposition of atmospheric ${ }^{10} \mathrm{Be}$, Atmos. Chem. Phys., 9, 515527, 2009,

http://www.atmos-chem-phys.net/9/515/2009/.

Heintzenberg, J., Covert, D. C., and van Dingenen, R.: Size distributions and chemical composition of marine aerosols: a composition and review, Tellus, 52B, 1104-1122, 2000.

Holben, B. N., Eck, T. F., Slutsker, I., Tanre, D., Buis, J. P., Setzer, A., Vermote, E., Reagan, J. A., Kaufman, Y. J., Nakajima, T., Lavenu, F., Jankowiak, I., and Smirnov, A.: AERONET - A federated instrument network and data archive for aerosol characterization, Remote Sens. Environ., 66, 1-16, 1998.

Hoose, C., Lohmann, U., Bennartz, R., Croft, B., and Lesins, G.: Global simulations of aerosol processing in clouds, Atmos. Chem. Phys., 8, 6939-6963, 2008a, http://www.atmos-chem-phys.net/8/6939/2008/.

Hoose, C., Lohmann, U., Stier, P., Verheggen, B., and Weingartner, E.: Aerosol processing in mixed-phase clouds in ECHAM5HAM: Model description and comparison to obserations, J. Geophys. Res., 113, D07210, doi:10.1029/2007JD009251, 2008 b.

Jacobson, M. Z.: Development of mixed-phase clouds from multiple aerosol size distributions and the effect of the clouds on aerosol removal, J. Geophys. Res., 108(D8), 4245, doi:10.1029/2002JD002691, 2003. 
Koch, D., Jacob, D., and Graustein, W.: Vertical transport of tropospheric aerosols as indicated by ${ }^{7} \mathrm{Be}$ and ${ }^{210} \mathrm{~Pb}$ in a chemical tracer model, J. Geophys. Res., 101(D13), 18651-18666, 1996.

Koch, D., Schmidt, G. A., and Field, C. V.: Sulfur, sea salt, and radionuclide aerosols in GISS ModelE, J. Geophys. Res., 111, D12209, doi:10.1029/2005JD006899, 2006.

Koch, D., Schulz, M., Kinne, S., McNaughton, C., Spackman, J. R., Balkanski, Y., Bauer, S., Berntsen, T., Bond, T. C., Boucher, O., Chin, M., Clarke, A., De Luca, N., Dentener, F., Diehl, T., Dubovik, O., Easter, R., Fahey, D. W., Feichter, J., Fillmore, D., Freitag, S., Ghan, S., Ginoux, P., Gong, S., Horowitz, L., Iversen, T., Kirkevåg, A., Klimont, Z., Kondo, Y., Krol, M., Liu, X., Miller, R., Montanaro, V., Moteki, N., Myhre, G., Penner, J. E., Perlwitz, J., Pitari, G., Reddy, S., Sahu, L., Sakamoto, H., Schuster, G., Schwarz, J. P., Seland, Ø., Stier, P., Takegawa, N., Takemura, T., Textor, C., van Aardenne, J. A., and Zhao, Y.: Evaluation of black carbon estimations in global aerosol models, Atmos. Chem. Phys., 9, 9001-9026, 2009,

http://www.atmos-chem-phys.net/9/9001/2009/.

Koch, D., Schulz, M., Kinne, S., McNaughton, C., Spackman, J. R., Balkanski, Y., Bauer, S., Berntsen, T., Bond, T. C., Boucher, O., Chin, M., Clarke, A., De Luca, N., Dentener, F., Diehl, T., Dubovik, O., Easter, R., Fahey, D. W., Feichter, J., Fillmore, D., Freitag, S., Ghan, S., Ginoux, P., Gong, S., Horowitz, L., Iversen, T., Kirkevåg, A., Klimont, Z., Kondo, Y., Krol, M., Liu, X., Miller, R., Montanaro, V., Moteki, N., Myhre, G., Penner, J. E., Perlwitz, J., Pitari, G., Reddy, S., Sahu, L., Sakamoto, H., Schuster, G., Schwarz, J. P., Seland, Ø., Stier, P., Takegawa, N., Takemura, T., Textor, C., van Aardenne, J. A., and Zhao, Y.: Corrigendum to "Evaluation of black carbon estimations in global aerosol models" published in Atmos. Chem. Phys., 9, 9001-9026, 2009, Atmos. Chem. Phys., 10, 79-81, 2010,

http://www.atmos-chem-phys.net/10/79/2010/.

Kownacka, L.: Vertical distributions of beryllium-7 and lead-210 in the tropospheric and lower stratospheric air, Nukleonika, 47, 79-82, 2002.

Levy, R. C., Remer, L. A., Mattoo, S., Vermote, E. F., and Kaufman, Y. J.: Second-generation operational algorithm: Retrieval of aerosol properties over land from inversion of Moderate Resolution Imaging Spectroradiometer spectral reflectance, J. Geophys. Res., 112, D13211, doi:10.1029/2006JD007811, 2007.

Lin, S. J. and Rood, R. B.: Multidimensional flux form semiLagrangian transport, Mon. Weather Rev., 124, 2046-2068, 1996.

Liu, H., Jacob, D. J., Bey, I., and Yantosca, R. M.: Constraints from $210 \mathrm{~Pb}$ and $7 \mathrm{Be}$ on wet deposition and transport in a global three-dimensional chemical tracer model driven by assimilated meteorolgical fields, J. Geophys. Res., 106, 12109-12128, 2001.

Lohmann, U. and Kärcher, B.: First interactive simulations of cirrus clouds formed by homogeneous freezing in the ECHAM general circulation model, J. Geophys. Res., 107(D10), 4105, doi:10.1029/2001JD000767, 2002.

Lohmann, U., Stier, P., Hoose, C., Ferrachat, S., Kloster, S., Roeckner, E., and Zhang, J.: Cloud microphysics and aerosol indirect effects in the global climate model ECHAM5-HAM, Atmos. Chem. Phys., 7, 3425-3446, 2007,

http://www.atmos-chem-phys.net/7/3425/2007/.
Lohmann, U., Spichtinger, P., Jess, S., Peter, T., and Smit, H.: Cirrus cloud formation and ice supersaturated regions in a global climate model, Environ. Res. Lett., 3, 045022(11pp), doi:10.1088/1748-9326/3/4/045022, 2008.

Martin, J. J., Wang, P. K., and Pruppacher, H. R.: A theoretical determination of the efficiency with which aerosol particles are collected by simple ice crystal plates, J. Atmos. Sci., 37, 16281638, 1980.

Martonchik, J. V., Diner, D. J., Crean, K. A., and Bull, M. A.: Regional aerosol retrieval results from MISR, IEEE T. Geosci. Remote, 40, 1520-1531, 2002.

Masarik, J. and Beer, J.: Simulation of particle fluxes and cosmogenic nuclide production in the Earth's atmosphere, J. Geophys. Res., 104, 12099-12111, 1999.

Miller, N. L. and Wang, P. K.: Theoretical determination of the efficiency of aerosol particle collection by falling columnar ice crystals, J. Atmos. Sci., 46, 1656-1663, 1989.

Miller, N. L. and Wang, P. K.: A theoretical determination of the collection rates of aerosol particles by falling ice crystal plates and columns, Atmos. Environ., 25A, 2593-2606, 1991.

Mlawer, E. J., Taubman, S. J., Brown, P. D., Iacono, M. J., and Clough, S. A.: Radiative transfer for inhomogeneous atmosphere: RRTM, a validated correlated-k model for the longwave, J. Geophys. Res., 102, 16663-16682, 1997.

Morcrette, J.-J., Clough, S. A., Mlawer, E. J., and Iacono, M. J.: Impact of a validated radiative transfer scheme, RRTM, on the ECMWF model cliamte and 10-day forecasts, ECMWF, Reading, UK, technical memorandum 252 edn., 1998.

Nordeng, T. E.: Extended versions of the convective parameterization scheme ay ECWMF and their impact on the mean and transient activity of the model in the tropics, ECMWF, Reading, UK, technical memorandum edn., 1994.

Pruppacher, H. R. and Klett, J. D.: Microphysics of clouds and precipitation., Kluwer Academic Publishers, Dordrecht, Boston, London, 1997.

Remer, L. A., Kaufman, Y. J., Tanre, D., Mattoo, S., Chu, D. A., Martins, J. V., Li, R.-R., Ichoku, C., Levy, R. C., Kleidman, R. G., Eck, T. F., Vermote, E., and Holben, B. N.: The MODIS aerosol algorithm, products and validation, J. Atmos. Sci., 62, 947-973, 2005.

Roeckner, E., Bäuml, G., Bonaventura, L., Brokopf, R., Esch, M., Giorgetta, M., Hagemann, S., Kirchner, I., Kornblueh, L., Manzini, E., Rhodin, A., Schlese, U., Schulzweida, U., and Tompkins, A.: The atmospheric general circulation model ECHAM5, PART I: Model description, Tech. Rep. 349, MaxPlanck-Inst. für Meteorol., Hamburg, Germany, 2003.

Spichtinger, P. and Gierens, K. M.: Modelling of cirrus clouds Part 1a: Model description and validation, Atmos. Chem. Phys., 9, 685-706, 2009, http://www.atmos-chem-phys.net/9/685/2009/.

Stier, P., Feichter, J., Kinne, S., Kloster, S., Vignati, E., Wilson, J., Ganzeveld, L., Tegen, I., Werner, M., Balkanski, Y., Schulz, M., Boucher, O., Minikin, A., and Petzold, A.: The aerosolclimate model ECHAM5-HAM, Atmos. Chem. Phys., 5, 11251156, 2005, http://www.atmos-chem-phys.net/5/1125/2005/. 
Takemura, T., Nakajima, T., Dubovik, O., Holben, B. N., and Kinne, S.: Single scattering albedo and radiative forcing of various aerosol species with a global three-dimensional model, J. Climate, 15, 333-352, 2002.

Textor, C., Schulz, M., Guibert, S., Kinne, S., Balkanski, Y., Bauer, S., Berntsen, T., Berglen, T., Boucher, O., Chin, M., Dentener, F., Diehl, T., Easter, R., Feichter, H., Fillmore, D., Ghan, S., Ginoux, P., Gong, S., Grini, A., Hendricks, J., Horowitz, L., Huang, P., Isaksen, I., Iversen, I., Kloster, S., Koch, D., Kirkevåg, A., Kristjansson, J. E., Krol, M., Lauer, A., Lamarque, J. F., Liu, X., Montanaro, V., Myhre, G., Penner, J., Pitari, G., Reddy, S., Seland, Ø., Stier, P., Takemura, T., and Tie, X.: Analysis and quantification of the diversities of aerosol life cycles within AeroCom, Atmos. Chem. Phys., 6, 1777-1813, 2006,

http://www.atmos-chem-phys.net/6/1777/2006/.
Tie, X., Madronich, S., Walters, S., Edwards, D. P., Ginoux, P., Mahowald, N., Zhang, R. Y., Lou, C., and Brasseur, G.: Assessment of the global impact of aerosols on tropospheric oxidants, J. Geophys. Res., 110, D03204, doi:10.1029/2004JD005359, 2005.

Tiedtke, M.: A comprehensive mass flux scheme for cumulus parameterization in large scale model, Mon. Weather Rev., 117, 1779-1800, 1989.

Twomey, S.: Aerosol, clouds, and radiation, Atmos. Environ., 25A, 2435-2442, 1991.

van Donkelaar, A., Martin, R. V., Brauer, M., Kahn, R., Levy, R., Verduzco, C., and Villeneuve, P.: Global estimates of average ground-level fine particulate matter concentrations from satellitebased aerosol optical depth, Environ. Health Persp., submitted, 2010.

Wang, P. K., Grover, S. N., and Pruppacher, H. R.: On the effect of electric charges on the scavenging of aerosol particles by clouds and small raindrops, J. Atmos. Sci., 35, 1735-1743, 1978. 